\title{
Los indicadores ambientales para la medición del desarrollo sostenible de Tierra del Fuego
}

\section{The environmental indicators for measuring the sustainable development of Tierra del Fuego}

\author{
Mariano HERMIDA ${ }^{1}$, mhermida@ untdf.edu.ar \\ Mercedes MANTÉ2 ${ }^{2}$ mmante@untdf.edu.ar \\ ${ }^{1}$ Instituto de Cultura, Sociedad y Estado (ICSE) - Universidad Nacional de Tierra del Fuego \\ (UNTDF). ${ }^{2}$ Instituto de Ciencias Polares, Ambiente y Recursos Naturales (ICPA) - \\ Universidad Nacional de Tierra del Fuego (UNTDF)
}

Recibido: 26/11/2018. Aceptado: 03/04/2019

\section{RESUMEN}

La gestión de la información es un insumo básico para el diseño y monitoreo de las políticas públicas para el desarrollo sostenible. En este contexto la provincia de Tierra del Fuego presenta un espacio fértil para el diseño de sistemas de información. De esta forma en el presente documento nos proponemos dar cuenta de la selección y consolidación de indicadores para la medición del subsistema ambiental y su relación con las restantes dimensiones, la social, la económica y la institucional, todas inherentes al concepto del desarrollo sostenible. Para ello abordaremos distintos elementos. Por un lado, realizaremos un recorrido teórico conceptual que permita establecer los criterios del desarrollo sostenible y de las componentes del sistema de información. Por el otro seleccionaremos las herramientas metodológicas necesarias para la composición del sistema, principalmente estructurada por abordajes cualitativos comprendidos por el análisis teórico comparativo y la definición de meta información de los distintos indicadores, la cual es acompañada por entrevistas en profundidad a informantes clave.

Palabras clave: sistema de información; desarrollo sostenible; indicadores ambientales.

\begin{abstract}
The management of information is a basic input for the design and monitoring of public policies for sustainable development. In this context, the province of Tierra del Fuego, Argentina, presents a fertile place for the design of information systems. Thus, in this document, we propose to account for the selection and consolidation of indicators for the measurement of the environmental subsystem and its relationship with the other dimensions, social, economic and institutional, all they are inherent in the concept of sustainable development. For this we will address different elements. On the one way, we will carry out a conceptual theoretical journey that will establish the criteria of sustainable development and the components of the information system. On the other way, we will select the methodological tools necessary for the composition of the system, mainly structured by qualitative approaches comprised by the theoretical comparative analysis and the definition of meta information of the different indicators, which is accompanied by in-depth interviews with key informants.
\end{abstract}


Key words: information system; sustainable development; environmental indicators.

\section{INTRODUCCIÓN}

El presente artículo es se propone dar cuenta de la selección y consolidación de indicadores para la medición del subsistema ambiental y su relación con las restantes dimensiones, la social, la económica y la institucional para un sistema de información estadística que permita la planificación, monitoreo y medición del desarrollo local sostenible en la Provincia de Tierra del Fuego.

La provincia más austral de la República Argentina presenta la particularidad de sostener un alto crecimiento poblacional y económico desde que fue sancionada la ley 19.640 de promoción industrial en el año 1972 (Carpinetti, 2003; Hermida et al, 2016). Ese proceso, basado en una concepción netamente geopolítica de poblar el territorio (Schorr y Puricelli, 2014), condujo a un crecimiento aparentemente exógeno (Madoery, 2016; Hermida, 2015). Este proceso tiene importantes impactos en términos ambientales, lo que resulta una dimensión importante para su medición y monitoreo constante.

Por otro lado, alcanzar el desarrollo sostenible es un objetivo hacia el cual están dirigidas las agendas internacionales de elaboración de políticas públicas de las últimas décadas. En este marco surge la necesidad de contar con información estadística como insumo imprescindible para el diseño, elaboración y monitoreo de las políticas públicas en los ámbitos locales. Dicho requerimiento se asocia a la falta de enfoques que den cuenta de un modelo de análisis integral en el que se relacionen diferentes dimensiones que contribuyan a la toma de decisiones.

Esto induce a un debate sobre el que debemos plantearnos algunos interrogantes. ¿Cuál es la dinámica ambiental de la provincia? Y de esta forma, ¿Qué indicadores presentan la capacidad de medir y monitorear la dimensión ambiental en términos de desarrollo sostenible? Por último y no menos importante ¿La información estadística disponible en la provincia contribuye a realizar monitoreos de la dimensión en análisis para el concepto descrito?

De acuerdo a nuestro criterio y siguiendo a Cavuoto (2009, p. 176), la información estadística es uno de los insumos sustanciales para la producción de conocimiento, el diseño y el monitoreo de políticas públicas. A su vez, la democratización de la misma permite a la sociedad civil debatir acerca de qué tipo de desarrollo es el que considera conveniente. En este sentido un sistema de información estadística pública se hace sumamente necesario para que la sociedad fueguina pueda gestar un desarrollo sostenible y endógeno.

De la misma manera, y remitiendo a Senn (1992), un sistema de información estadística permite a los tomadores de decisión, entre los que se incluye a la sociedad civil en general, establecer políticas que se encuentren basadas en datos. El conocimiento es la mejor herramienta para el desarrollo democrático e inclusivo, en términos del Estado como articulador, para el sector privado como gestor de sus lineamientos productivos, y para la ciudadanía como observador y decisor del tipo de desarrollo que pretende.

De esta forma exhibiremos los elementos y herramientas, tanto teóricas como metodológicas, que fueron necesarias para seleccionar los indicadores pertenecientes a la dimensión 
ambiental del sistema de información estadística que permita el monitoreo del desarrollo local sostenible en la Provincia de Tierra del Fuego.

La organización del presente artículo se estableció en dos apartados principales, subdivididos en segmentos, y las correspondientes conclusiones de la investigación. El primero de los apartados abarca el marco histórico y conceptual para la elaboración del sistema de información para la medición del desarrollo sostenible en la Provincia de Tierra del Fuego. Allí se incluyó un primer y segundo segmento que recorren el devenir histórico del concepto y la ampliación de sus dimensiones, un tercer segmento con los marcos conceptuales ordenadores para el sistema, un cuarto segmento con los criterios y metodologías utilizadas para la selección de los indicadores, y un quito segmento descriptivo de las características de la provincia. El segundo apartado recoge los resultados obtenidos en la investigación, primero en la presentación cuantitativa de los indicadores evaluados, seguido de un segundo y tercer segmento con los indicadores seleccionados para la dimensión ambiental y la relación de esta con las restantes dimensiones comprendidas en el concepto.

Consideramos que el presente trabajo, aunque se basa en un estudio de caso, será de utilidad para contribuir al debate internacional acerca de los sistemas de información que conlleva el proceso de operacionalización (Lazarfeld, 1973; Mayntz, 1985) de un concepto complejo como el del desarrollo local sostenible, el cuál se encuentra en la agenda de análisis gubernamental y de los organismos estadísticos, desde que fueran sancionados los 17 Objetivos del Desarrollo Sostenible en Septiembre 2015 ${ }^{1}$ (ONU, 2015; Manté y Hermida, 2016).

\section{EL MARCO HISTÓRICO Y CONCEPTUAL PARA EL SISTEMA DE INFORMACIÓN}

Esta segunda sección comprende el marco histórico y la ampliación de las dimensiones por las que atravesó el concepto del desarrollo sostenible, en este devenir se estructuraron los marcos conceptuales ordenadores utilizados para la medición del concepto. Finalmente se incluyeron los criterios y las metodologías necesarias para la selección de los indicadores, así como una breve descripción de la Provincia de Tierra del Fuego.

\subsection{Desarrollo local sostenible}

El crecimiento económico atravesó un proceso de ampliación en sus dimensiones. Como hijo del proceso de revolución industrial originada desde mediados del siglo XVIII, y profundizado con el desarrollo industrial de los países occidentales entre la segunda parte del siglo XIX y principios del XX, comenzó a separarse del simple crecimiento de la riqueza de bienes y servicios, para aplicarse en una perspectiva más humana y social hacia finales de la segunda guerra mundial. Sin embargo desde principios de la década del '70 comienzan a hacerse visibles los impactos en el ambiente, y un espíritu crítico empieza a entender que el desarrollo no se da de la mano de la acumulación de riqueza (Hermida, 2015). Para ello, tanto desde la CEPAL (Svampa, 2009), como desde el Modelo Mundial Latinoamericano proponen

\footnotetext{
${ }^{1}$ En la actualidad los países miembros de la Organización de las Naciones Unidas se encuentran en el proceso de adecuación de los 17 objetivos y las 169 metas a su realidad local (CNCPS, 2016a). Este trabajo establece la agenda y medición de políticas públicas nacionales para el 2017 y provinciales para 2019 (CNCPS, 2016b), con lo cual la coyuntura y vigor del debate nos es sustancial para el desarrollo de las actividades en términos de sostenibilidad socioeconómica y ambiental.
} 
una visión distinta a los "límites del crecimiento" propuesto por el Club de Roma (Goñi y Goin, 2006).

El debate desarrollado desde la cumbre de Estocolmo en 1972 parece tener un primer resultado en el famoso Informe Bruntland ("Nuestro futuro común") redactado por las Naciones Unidas en 1987 (ONU, 1987). Es en él donde el término "desarrollo sostenible" comenzó a tener una rápida y amplia difusión. Sin embargo el concepto termina siendo amplio y hasta ambiguo, asociado a la idea de progreso pero circunscripto a la finitud de los recursos naturales. También global ya que supone una mirada que contemple la diversidad, tanto social, económica, ambiental, como la local, nacional o regional.

Desde nuestra perspectiva parece necesario diferenciar al desarrollo del manejo sostenible, este último puede estar basado en las pautas de baja degradación del ambiente, pero no contemplar derechos sociales. "Esto significa que no es que la sociedad realiza el desarrollo sostenible del ambiente, sino que el desarrollo sostenible de la sociedad incluye, entre otras, una dimensión ambiental”. (Reboratti, 2000, p. 199-200)

Ahora bien hemos observado que el desarrollo sostenible no sólo contiene una perspectiva nacional o global, sino también local. Así surge la pregunta: ¿local refiere a municipal? Desde la óptica que perseguimos, entendemos que desarrollo local no es el equivalente de desarrollo municipal. Claro está que es imposible la sostenibilidad territorial si en una jurisdicción existe un manejo sustentable y en otra no, o si en una se ejecutan políticas de desarrollo social y otra simplemente políticas de sobre el manejo, evidentemente los niveles jurisdiccionales deben trabajar mancomunadamente a fin de consolidar un desarrollo global. En este sentido lo territorial no debe estar sometido al corsé del límite jurisdiccional. Sin embargo es necesario señalar que el gobierno local debe ser un actor central, dadas las virtudes de sus competencias, gran parte del "éxito" del desarrollo depende de su accionar (Quetglas, 2008, p. 29-30). En este marco el desarrollo local sostenible se traduce en un proceso endógeno, que se genera en el interior de la sociedad, que mantiene el diálogo con el afuera, pero que no es impuesto desde "arriba".

De más está decir que entendemos que desarrollo no es sinónimo de crecimiento, el primero puede contener al segundo, pero el segundo no necesariamente al primero. Por ejemplo, crecimiento del Producto Bruto Interno no significa distribución de la riqueza, ni tampoco reducción de la pobreza, que sí deben ser contenidos necesariamente por el desarrollo. En este sentido el desarrollo sostenible debe apuntar a reducir la desigualdad social.

El desarrollo sostenible comprende la relación entre la sociedad civil y el ambiente (Reboratti, 2000). En este sentido e introduciendo una perspectiva sistémica, observamos la relación del ser humano como sujeto y parte del ambiente en constante relación con él. Desde esta perspectiva no entendemos a la relación como competencia desde los sistemas (Bucley, 1982, p. 30), sino en una continua relación.

Por supuesto esa relación es diferencial y asimétrica ya que es la sociedad quien interviene en el ambiente modificándolo. Sin embargo esa intervención puede ser sostenible o no dependiendo del tipo de manejo que se realice del ambiente. En este sentido puede darse un estado de equilibro o de homeostasis, que "no implica fijeza, inmovilidad o estancamiento, sino que significa una condición que puede variar, pero es relativamente constante" (Bucley, 1982, p. 32), es decir que el cambio es parte necesaria de los sistemas, sin embargo ese cambio puede ocurrir en un marco de equilibrio o compensación. 
A fin de aclarar el concepto, Hopwood, Mellor y O'Brien (2005) establecen un mapa de las distintas aproximaciones que recibe el concepto del desarrollo sostenible. En dicho artículo los autores diferencian los abordajes en dos niveles, la relación equidad o inequidad en términos de desarrollo socioeconómico y la relación centrada o no en términos ambientales. Este análisis relacional les permite diferenciar los abordajes teóricos que sostienen el "status quo", los que apelan a una visión reformista, y quienes se resuelven por la transformación completa. En el centro del esquema el modelo encuentra a las corrientes emergentes al Informe Brundtland, en la base de la inequidad y la desatención ambiental se aprecia el abordaje neoliberal, el Club de Roma se presenta igualmente inequitativo, aunque eco centrado. Finalmente los movimientos latinoamericanos son situados en los extremos de la transformación, es decir centrados en la protección ambiental con una fuerte inclusión socio económica para el desarrollo.

Finalmente, y siguiendo a Gallopín (2003), desarrollo sostenible se aprecia cuando el crecimiento económico no material o crecimiento cero (alternativa para países "ricos") se reúne con las mejoras en la calidad de vida. Dentro de sus acepciones observa la posibilidad de que los países que denomina "pobres" generen crecimiento económico material con una calidad de vida creciente, según su apreciación dicho grupo de países requiere que la sostenibilidad se cristalice principalmente en la erradicación de la pobreza y en la mejora de las condiciones materiales de la población.

La pregunta que probablemente se hará el lector es si este proceso propuesto es posible, cabe destacar que el autor de la tipología enfatiza en la distribución por sobre el crecimiento en aquellos países con altos niveles de desarrollo, de esta forma se reduce la presión sobre el ambiente y se hace sostenible tanto desde el punto de vista de los recursos naturales como desde la perspectiva en la equidad social. Para aquellos países que no han llegado a un nivel de desarrollo tan elevado la propuesta es mantener los niveles de crecimiento material elevando la distribución de la riqueza, si esto no ocurre es imposible hacer sostenible el desarrollo.

\subsection{Las dimensiones del desarrollo sostenible}

Tal como observamos en las páginas precedentes, consideramos al desarrollo sostenible como un concepto compuesto por el crecimiento económico, la observación del ambiente, la equidad social, y el marco de institucionalidad (Arocena, 2009, p. 17). Estas dimensiones son las que componen el Prisma de Sostenibilidad (Aguado, Barrutia y Echebarria, 2008, p. 6). Desde este lugar el concepto requiere que sea concretizado, para ello hemos de exigirle una definición que sea traducible en indicadores que permitan medir su evolución y las posibilidades que brinda el territorio y sus actores para que ocurra.

Este modelo multidimensional expresado en el Esquema 1 permite aproximar la riqueza que el concepto de desarrollo debería contener. Por este motivo si se enfatiza sólo en una de las dimensiones, sea este el crecimiento económico, o la equidad social, o simplemente se cuida el ambiente, o se resguarda las instituciones, alguno de las partes se va a ver desbalanceada y el desarrollo no será completo. En este sentido es esencial que el lector entienda por desarrollo al desarrollo sostenible en su multidimensionalidad. 


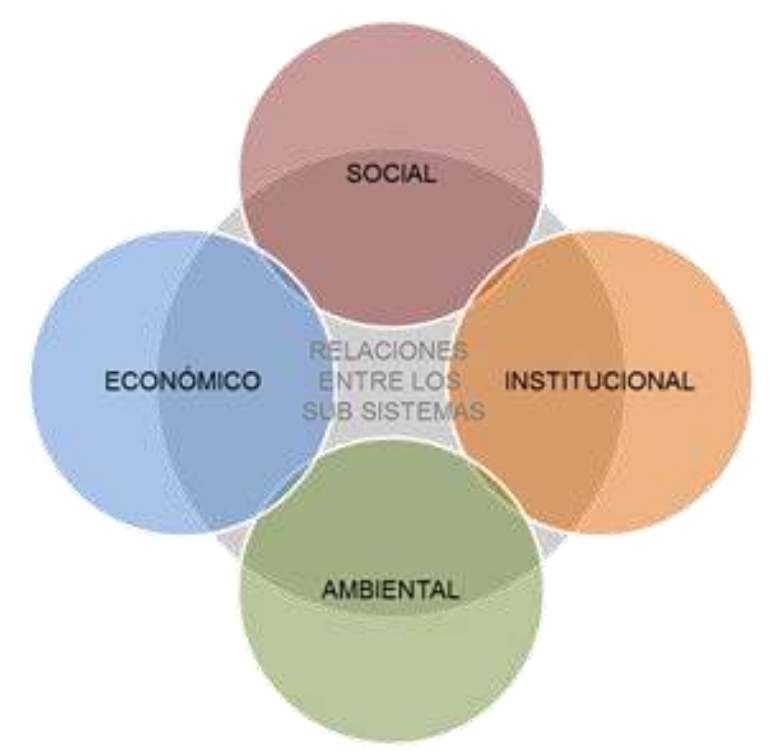

Esquema 1. Sistema de desarrollo sostenible Fuente: Elaboración propia en base a Gallopín (2003)

De más está decir que en este espacio no nos proponemos fijar las metas del desarrollo sostenible sino establecer las dimensiones que se contienen en dicho desarrollo a fin de que diferentes sectores de la sociedad puedan establecer las metas de dicho proceso (Gallopín, 2003). Desde una perspectiva sistémica cada una de estas dimensiones implica un subsistema que tienen funciones o relaciones entre ellos.

En este sentido el modelo que proponemos se relaciona de forma temática con los Objetivos del Desarrollo Sostenible (ODS), estos conforman la agenda propuesta para los países miembros de Naciones Unidas hacia 2030 (Manté y Hermida, 2016). Si bien los ODS cuentan con una serie de indicadores específicos para cada uno de los 17 objetivos y 169 metas, el presente modelo se propone un diálogo con dicha agenda pero no se encuentra anclada en ella, es decir se relaciona con la tradición del desarrollo sostenible pero no es subsidiaria directa de las propuestas realizadas en septiembre de 2015 (ONU, 2015), y que en la actualidad se encuentra en proceso de adecuación a las realidades locales (CNCPS, 2016a, 2016b).

\subsection{Marcos conceptuales ordenadores}

Se suele recomendar que los indicadores estén ordenados siguiendo un marco conceptual, este ordenamiento explota la utilidad de los indicadores y permite su mejor interpretación. En este sentido los marcos organizan los indicadores de forma coherente, compatibilizan a los mismos, guían la recolección de información, sugieren agrupamientos lógicos para la integración, permiten identificar los huecos, distribuyen la carga y comunican de forma sintética la información facilitando la visualización a los tomadores de decisión (Gallopín, 2006, p. 20).

En este apartado observaremos los diferentes marcos ordenadores existentes a fin de establecer el más apropiado para el diseño del sistema de indicadores que dé cuenta con el monitoreo del desarrollo local sostenible de Tierra del Fuego.

Uno de los primeros marcos en ser utilizados fue el de Presión-Estado-Respuesta (PER), diseñado por la Comisión de Desarrollo Sostenible (CDS) de las Naciones Unidas. Este marco 
fue utilizado principalmente para los indicadores ambientales, en donde la "presión" se refiere al ejercicio que hacen las actividades humanas sobre el ambiente, siendo el "estado" la condición en la que se encuentra ese ambiente, y la "respuesta" a las medidas de regulación que la sociedad hace para "mantener" ese ambiente. Algunas variantes a este modelo son los marcos de Fuerza Motriz-Estado-Respuesta (FER), Fuerza Motriz-Presión-Estado-Respuesta (FPER), Fuerza Motriz-Presión-Estado-Impacto-Respuesta (FPEIR) (Gómez et al, 2012).

Todos estos marcos, pero principalmente el PER, presentan dos inconvenientes: la primera radica en que se encuentran basados en un esquema de causalidad lineal, lo que estaría ignorando las complejidades de las relaciones, especialmente la que se da entre la sociedad y la naturaleza, es decir el intercambio con el ambiente. De esta forma se ignoran las causalidades múltiples y no lineales, lo que hace extremadamente complicada la selección de indicadores que den cuenta con cada proceso. El segundo punto refiere a la falta de observación de la multidimensionalidad que el concepto de desarrollo sostenible conlleva. Tal como observamos anteriormente las dimensiones incluidas en el análisis son cuatro, por lo que los indicadores deben dar cuenta de todas ellas, tanto lo social, económico, institucional, como lo ambiental. Los modelos PER y sus variantes no tienen en cuenta todas las dimensiones a la vez, sino que enfatizan en el efecto que produce el ser humano sobre el ambiente, y pierden de vista cual es la sostenibilidad del sistema social. (Gallopín, 2006, p. 21-22)

Estos modelos de primera generación fueron seguidos por unos de segunda generación utilizados a partir de la década de los noventa, en el proceso de desarrollo de sistemas a nivel nacional. Estos marcos incorporan el enfoque multidimensional (económico, ambiental y social) del desarrollo sostenible, y en los últimos años introdujeron una cuarta dimensión, la institucional. (Sotelo et al, 2011, p. 615)

La tercera y última generación surge en la necesidad de vincular las dimensiones del desarrollo y de sus indicadores entre sí, así se generaron sistemas de indicadores que permiten tener un "acceso rápido a un mundo de significados mucho mayor, y que agrupen en temas o áreas multidimensionales, de forma transversal y sistemática"2. (Sotelo et al, 2011, p. 616)

Dentro de este grupo se encuentra el modelo socio-ecológico de la CEPAL para la Evaluación de la Sostenibilidad de América Latina y el Caribe (ESALC), basado en una propuesta de Gilberto Gallopín (2006) y que tiene por objetivo apoyar la definición de políticas públicas tomadas por los países de la región y los organismos intervinientes, a través de una evaluación sistémica e integrada de los avances en materia de sostenibilidad del desarrollo, para ello se integran indicadores ambientales, sociales, económicos e institucionales, en un marco sistémico.

Este marco se encuentra basado en el concepto de sistema socio-ecológico dado que entiende que la resolución de los problemas de sostenibilidad del desarrollo "requiere considerar el

\footnotetext{
${ }^{2}$ El primer marco realmente sistémico fue desarrollado por Herman Daly, conocido como el "Triángulo de Daly" (Barton, 2009: 9), en donde se relaciona la riqueza natural con el propósito ultimo de atender al bienestar de los seres humanos desde la tecnología, la economía, la política y la ética. "De acuerdo a este marco, las tres medidas agregadas más básicas del desarrollo sostenible son: la suficiencia con que las metas últimas son logradas para todos; la eficiencia con que los medios últimos se traducen en metas últimas; y la sostenibilidad del uso de los medios últimos". (Gallopín, 2006, p. 22-23) Otro modelo sistémico es el diseñado por Bossel, este modelo relaciona seis subsistemas yfue aplicado a sistemas de diferente escala. El tercer caso es el denominado Modelo Suizo o Monet. Este es un modelo de acervos y flujos utilizado para clasificar los indicadores de desarrollo sostenible. Contiene niveles, capitales, criterios definitorios y respuestas (Gallopín, 2006, p. 22-25).
} 
sistema total conformado por la naturaleza y la sociedad, incluyendo los subsistemas relevantes así como los vínculos entre los mismos. Tal sistema socio-ecológico puede considerarse la unidad básica de análisis para la problemática del desarrollo del sistema socioecológico total, sea a escala de país, de provincia, de localidad o del mundo". (Gallopín, 2006, p. 25)

De esta forma el marco ESALC cumple con las condiciones de ser multidimensional, atendiendo las relaciones sociedad-ambiente. Las cuatro dimensiones ampliamente reconocidas, y planteadas por la Comisión de Desarrollo Sostenible de Naciones Unidas y en gran parte de la bibliografía antes revisada, fueron conformados en cuatro sub sistemas, el social, el económico, el institucional y el ambiental. Tal como hemos observado en el Esquema 1, los sub sistemas se encuentran relacionados entre sí, lo que requiere que se mida cada sub sistema, la relación existente entre ellos y la eficiencia general del sistema. Para clarificar el significado que reviste cada uno adjuntamos la tabla 1:

Tabla 1. Características de los subsistemas

\begin{tabular}{ll} 
Sub sistema & Características \\
\hline Social & $\begin{array}{l}\text { Definido en sentido amplio como incluyendo las variables de calidad de vida } \\
\text { (satisfacción de las necesidades materiales y no materiales del ser humano) de la } \\
\text { renta y de su distribución y de los aspectos demográficos }\end{array}$ \\
Económico & $\begin{array}{l}\text { Incluye la producción y consumo de bienes y servicios, el comercio, el estado } \\
\text { general de la economía, la infraestructura y los asentamientos humanos y los } \\
\text { desechos generados por el consumo y la producción } \\
\text { Institucional }\end{array}$ \\
\hline Ambiental & $\begin{array}{l}\text { Incluye el ambiente natural en sus aspectos de recursos naturales, procesos } \\
\text { ecológicos, las condiciones de soporte vital y la biodiversidad. }\end{array}$ \\
\hline
\end{tabular}

Fuente: Elaboración propia en base a Gallopín (2006)

La Teoría de Sistemas supone las relaciones entre los Sub Sistemas siempre que estos sean abiertos (Ritzer, 2001, p. 224), los flujos e interrelaciones que se han seleccionado para el modelo son lo más neutras y universales como fuera posible. El flujo económico-institucional representa interrelaciones políticas, legales, fijación de precios, investigación y desarrollo. El económico-ambiental expresa los flujos de bienes y servicios ambientales hacia la producción económica, y los desechos que se generan desde la producción y el consumo hacia el ambiente. Las relaciones entre económico-social incluyen los efectos del consumo sobre la calidad de vida, la oferta y demanda de empleo, los impactos del ambiente urbano sobre la calidad de vida. Los flujos institucional-social incluyen los efectos en la educación, la seguridad y el impacto de la calidad de vida sobre las instituciones. De lo ambiental a lo social, se enfatizan los efectos del primero sobre el segundo, entendiendo que en sentido inverso estaría contenido en la relación económico-ambiental. Finalmente lo institucionalambiental incluye las áreas protegidas, los impactos ambientales por acciones militares, etc. (SAyDS, 2005, p. 14-15)

Este modelo se encuentra expresado en el esquema 2 siguiendo el diseño original planteado por el Gilberto Gallopín (2006): 


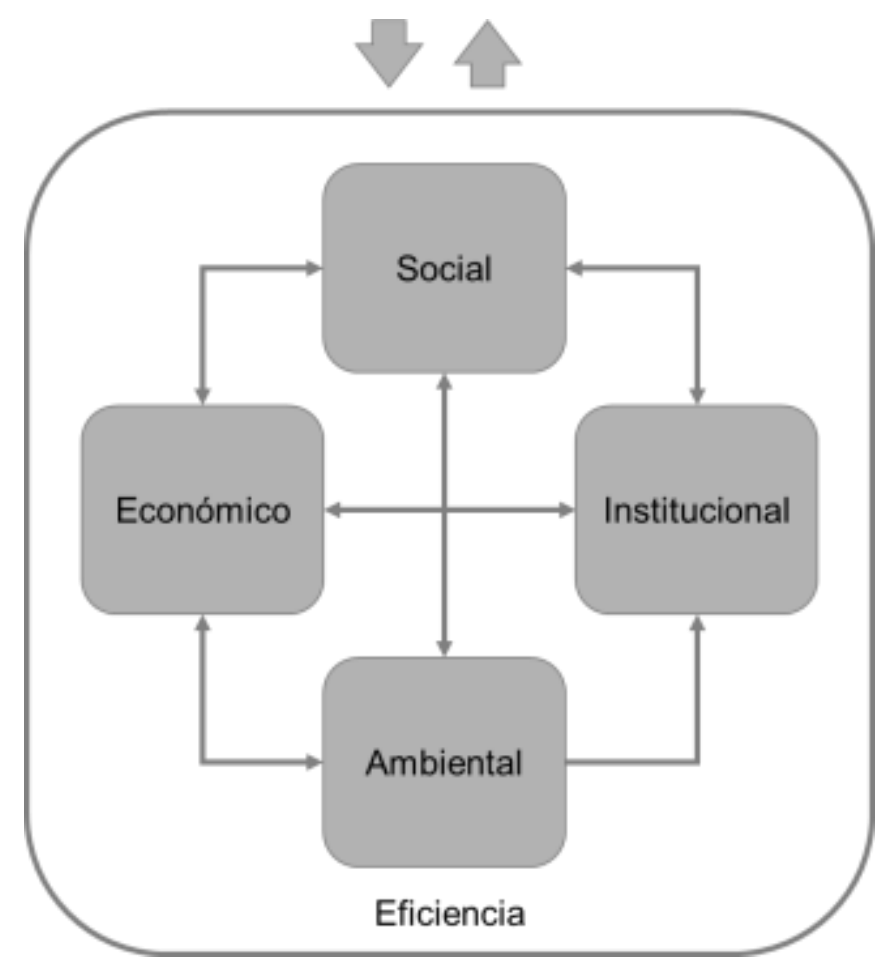

Esquema 2. Representación del sistema socio-ecológico Fuente: Elaboración propia en base a SAyDS (2005) y Gallopín (2006)

A modo de resumen un modelo basado en la teoría sistémica comprende:

- Vocabulario común a diferentes disciplinas científicas.

- Permite su aplicación a diferentes niveles, macro y micro.

- Comprende el análisis en su conjunto.

- Permite una perspectiva integradora.

- Realiza un enfoque de los procesos.

- Es dinámico.

- Entiende el cambio.

- Los sistemas suelen ser menos complejos que su entorno, es decir, reducen la complejidad. (Ritzer, 2001) ${ }^{3}$

Al realizar un análisis entre los distintos países observamos marcos de distintas generaciones, por ejemplo: el marco utilizado en Suecia hace énfasis en la eficiencia, la contribución a la igualdad, la adaptabilidad, valores y recursos para las generaciones futuras. En el caso de Francia, el marco se encuentra basado en el crecimiento económico, los acervos críticos de capital, la interfase global/local, las necesidades actuales y las futuras. Canadá adquiere la perspectiva del capital manufacturado, el capital natural y el capital humano. El marco holandés contiene los factores socio culturales, los financieros económico, y los ecológicos ambientales referidos al aquí y ahora. En América Latina existen algunas experiencias basadas en diferentes marcos, México se basa en el modelo PER, Uruguay ha presentado un modelo multidimensional, pero pondera principalmente lo ambiental, tanto Colombia, Brasil

\footnotetext{
${ }^{3}$ Si se desea ampliar la lectura sobre la Teoría de Sistemas, especialmente la aplicada a las ciencias sociales, o mejor dicho a las relaciones del ser humano con el ambiente recomendamos la lectura de Buckley, Walter. (1982) La sociología y la teoría moderna de los sistemas, Buenos Aires, Amorrortu Editores y García, R. (1994) "Interdisciplinariedad y sistemas complejos" en Leff, Enrique (comp.), Ciencias Sociales y Formación Ambiental, Ed. Gedisa, UNAM, Barcelona, España.
} 
como diferentes países de la región se encuentran en desarrollo de sus sistemas de indicadores, por lo que no se observan marcos concretos. Argentina ha optado desde 2005 el marco sistémico ESALC propuesto por la CEPAL, es decir uno de tercera generación.

En síntesis, observamos que el desarrollo local sostenible es un concepto complejo, por lo que una mirada holística basada en un modelo sistémico como marco ordenador de los indicadores parece ser la opción más indicada. Por otra parte hemos visto los problemas que han presentado los modelos causales de primera generación, y dado que se encuentra en práctica un modelo para Argentina, denominado el Sistema de Información del Desarrollo Sostenible de Argentina (SIDSA), llevado adelante por la Secretaría de Ambiente y Desarrollo Sustentable de la Nación (SAyDS 2005, 2010, 2015) que responde con el marco sistémico, y visto que este permite la aplicación tanto para niveles macro como micro, es decir tanto nacional como local, mantener el marco ESALC, se presenta como la mejor opción para un sistema de información para el desarrollo local sostenible en Tierra del Fuego.

\subsection{Criterios y metodologías utilizadas}

En el desarrollo de la investigación hemos utilizado abordajes metodológicos tanto del orden cualitativo como cuantitativo, tendiendo a una integración y hasta un modelo de triangulación metodológica (Piovani, 2008, Cook y Reichardt, 1986). En términos cuantitativos se procedió al procesamiento de los indicadores que no se encontraban calculados, para ello se utilizaron diferentes paquetes de análisis de datos estadísticos por computadora (Hernández Sampieri et al, 2010, Cea D’Ancona, 1996).

Asimismo, se realizó una evaluación cualitativa de los indicadores basada en los criterios establecidos por Rayen Quiroga Martínez (2009, p. 70-71):

- Criterios de relevancia

- Pertinencia para los problemas o decisiones en que se quiere utilizar los indicadores

- Relación con metas, objetivos o normas específicas que existan en el país o en otra escala territorial, que aterriza al indicador a la realidad en términos de políticas públicas e información ciudadana

- Criterios de viabilidad estadística

- Disponibilidad de información estadística necesaria para su cálculo

- Calidad de la información estadística necesaria para su cálculo

- Existencia y calidad de la descripción del indicador a través de los metadatos de las estadísticas necesarias para su cálculo

- Fortaleza del indicador en términos de su aceptación internacional o local basada en los criterios de calidad de la información y certeza científica de los fenómenos que pretende evidenciar

- Simplicidad, en el sentido de que los mejores indicadores son los que revelan la información en forma simple y directa

- Precisión y claridad, entendiéndose que los mejores indicadores muestran su significado en forma directa, clara y precisa

- Seguridad en la direccionalidad, en el sentido de que lo que muestre el valor del indicador a través del tiempo o de los territorios, sea consistente con lo que se quiere mostrar.

- Criterios Formales

- Consistencia interna de la ficha metodológica, lo que implica que todos y cada uno de los campos de la ficha, por ejemplo: el nombre, la fórmula, la frase de 
tendencia, el gráfico y los desafíos de política, estén alineados en la misma dirección

- Optimización de diseño del gráfico, cartografía o representación elegida.

El modelo propuesto atendió tanto a los requerimientos de la dinámica local como a la exigencia de mantener cierta comparabilidad con modelos nacionales e internacionales, estableciendo un número acotado de indicadores que fueran pertinentes a la toma de decisiones. Esta complejidad estableció una evaluación metódica en la confección y diseño del sistema de información, de acuerdo con criterios específicos entre los que se encuentran la evaluación de calidad y disponibilidad de los datos, la pertinencia de los indicadores, la oportunidad, la comparabilidad y la especificidad, todos ellos criterios adecuados a las prácticas estadísticas aplicadas en el marco internacional.

Siguiendo los criterios antes señalados hemos evaluado los indicadores estableciendo: la comparabilidad con el Sistema de Indicadores del Desarrollo Sostenible de Argentina (SIDSA) elaborado por la Secretaría de Ambiente y Desarrollo Sustentable de la Nación (SAyDS 2005; 2010; 2015), la disponibilidad de los datos para Tierra del Fuego, el nivel de desagregación, la periodicidad de publicación, la serie de tiempo disponible, la accesibilidad a los datos, las unidades de medida y de análisis, y finalmente la relevancia o pertinencia del indicador para el desarrollo sostenible.

Para dar cumplimiento a esta evaluación cualitativa se realizaron entrevistas en profundidad con guía semiestructurada ${ }^{4}$ (Valles, 1997) a informantes claves (investigadores, profesionales y productores de información $)^{5}$ con el objetivo de estimar la cobertura, la calidad y la pertinencia de la información existente, a fin de que la misma cumpla con los requisitos y estándares que deben presentar las estadísticas públicas. A su vez se realizaron otros abordajes cualitativos de tipo documental, bibliográfico y teórico, utilizados en el análisis del marco normativo e institucional y en la evaluación de indicadores.

Con estos insumos se confeccionó una grilla de evaluación. Esta herramienta de análisis fue de utilidad durante el desarrollo de la presente investigación y se fue completando en combinación con las técnicas cualitativas ya descriptas. Es así como se distinguió cuatro ejes primarios en la clasificación de indicadores:

- 1a) Imprescindibles ${ }^{6}$ con información disponible,

- 1b) Imprescindibles que se requieren construir en el mediano plazo,

- 2) Recomendables ${ }^{7}$ a construir a largo plazo y

- 3) Deseables ${ }^{8}$ a construir a largo plazo.

\footnotetext{
${ }^{4}$ La guía de entrevista constó de las siguientes preguntas: 1) ¿Le parece que este listado son los indicadores más representativos para la provincia? 2) ¿Qué indicador sacaría o agregaría? 3) ¿Quiénes podrían ser las fuentes de cada indicador? 4) ¿Esta información se encuentra disponible al público en general? 5) ¿Dónde se publica? o ¿Porqué no se publica? (ver esta pregunta según el desarrollo de la entrevista) 6) ¿Cuáles son sus consideraciones sobre un sistema de información o indicadores para el desarrollo sostenible basado en las cuatro dimensiones, social, económica, institucional y ambiental?

${ }^{5}$ El muestreo se realizó siguiendo los aportes conceptuales del muestreo teórico, por lo que se realizaron entrevistas hasta alcanzar la saturación teórica necesaria (Glaser y Strauss 1967), en total se entrevistaron 10 informantes claves.

${ }^{6}$ Se trata de indicadores básicos que resultan de primera prioridad a construir, dentro del amplio espectro de indicadores que se sugiere (Definición adaptada a partir de UNFPA, 2014, p. 38)

${ }^{7}$ Se trata de indicadores de segunda prioridad a construir, dentro del amplio espectro de indicadores que se sugiere (Definición adaptada a partir de UNFPA, 2014, p. 38)
} 
El cabezal de la grilla utilizada se estructuró siguiendo la tabla 2:

Tabla 2. Grilla de evaluación de indicadores

\begin{tabular}{|c|c|c|c|c|c|c|c|c|c|c|c|c|c|c|}
\hline $\begin{array}{l}\mathrm{N}^{\mathbf{0}} \\
\text { en } \\
\text { el } \\
\text { SI } \\
\text { DS } \\
\text { A }\end{array}$ & $\begin{array}{l}\mathrm{N}^{\mathrm{o}} \\
\text { en } \\
\text { el } \\
\text { SI } \\
\text { ED } \\
\mathrm{LS} \\
-\mathrm{T} \\
\mathrm{DF}\end{array}$ & $\begin{array}{l}\text { Dimensión } \\
\text { / Indicador }\end{array}$ & $\begin{array}{l}\text { Sel } \\
\text { ecc } \\
\text { ion } \\
\text { ad } \\
\text { o } \\
\text { par } \\
\text { a } \\
\text { TD } \\
\text { F }\end{array}$ & $\begin{array}{l}\text { Di } \\
\text { sp } \\
\text { oni } \\
\text { bili } \\
\text { da } \\
\text { d } \\
\text { par } \\
\text { a } \\
\text { TD } \\
\text { F }\end{array}$ & $\begin{array}{l}\mathrm{Ni} \\
\text { vel } \\
\text { de } \\
\text { des } \\
\text { agr } \\
\text { eg } \\
\text { aci } \\
\text { ón }\end{array}$ & $\begin{array}{l}\text { Per } \\
\text { iod } \\
\text { ici } \\
\text { da } \\
\text { d }\end{array}$ & $\begin{array}{l}\text { Añ } \\
\text { os } \\
\text { de } \\
\text { dis } \\
\text { po } \\
\text { nib } \\
\text { ilid } \\
\text { ad }\end{array}$ & $\begin{array}{l}\text { Ac } \\
\text { ces } \\
\text { ibil } \\
\text { ida } \\
\text { d }\end{array}$ & $\begin{array}{l}\text { Un } \\
\text { ida } \\
\text { d } \\
\text { de } \\
\text { me } \\
\text { did } \\
\text { a }\end{array}$ & $\begin{array}{l}\text { Un } \\
\text { ida } \\
\text { d } \\
\text { de } \\
\text { an } \\
\text { áli } \\
\text { sis }\end{array}$ & $\begin{array}{l}\text { Relevancia } \\
\text { o } \\
\text { Pertinencia } \\
\text { del } \\
\text { Indicador } \\
\text { para el } \\
\text { Desarrollo } \\
\text { Sostenible }\end{array}$ & $\begin{array}{l}\text { Motivo de } \\
\text { la no } \\
\text { selección }\end{array}$ & $\begin{array}{l}\mathrm{Fu} \\
\text { ent } \\
\mathrm{e}\end{array}$ & Observaciones \\
\hline
\end{tabular}

Fuente: Elaboración propia

Las cuales se definen como:

- $\mathrm{N}^{\circ}$ en el SIEDLS_TDF: Número asignado en el modelo Sistema de Información Estadística para el Desarrollo Local Sostenible (SIEDLS) para Tierra del Fuego.

- $\mathrm{N}^{\circ}$ en el SIDSA: Número original en el listado Sistema de Indicadores del Desarrollo Sostenible de Argentina (SIDSA) a fin de establecer su comparación con el modelo nacional.

- Dimensión / Indicador: Nombre o denominación del indicador o capítulo de la dimensión (sub sistema, interrelación, etc.)

- Seleccionado para TDF: Seleccionado para Tierra del Fuego con las categorías 1a (Imprescindibles con información disponible), 1b (Imprescindibles que se requieren construir en el mediano plazo), 2 (Recomendables a construir en el largo plazo) y 3 (Deseables a a construir en el largo plazo)

- Disponibilidad para TDF: categorías Si y No.

- Nivel de desagregación: Provincia (P) Departamento (D) Municipio (M)

- Periodicidad: Decenal (D), Anual (A), Trimestral (T), Mensual (M) y eventual (E) cuando no se expresa un período específico o el relevamiento se realizó una única vez.

- Años de disponibilidad: se especificó los años o períodos, por ejemplo en la información de fuente censal 2001-2010

- Accesibilidad: Accesible desde la web (W) Accesible por pedido (P) Accesible con dificultad (D) No accesible (No)

- Unidad de medida: (\%) Porcentaje, tasa o índice; (\%o) Tasa por mil, (P) Población (Hab) habitantes, (\$) Unidades monetarias (Kg) Peso, (ha) Hectáreas, (m2) metros cuadrados, (m3) metros cúbicos, (mm3) milímetros cúbicos (Mwh) mega watts hora, (hab) habitante, $(\mathrm{Pl})$ Plazas hoteleras, Días, Año, $(\mu)$ media

- Unidad de análisis: (\$) Pesos, Pesos/Población, media CPUE Centolla, Agua/Población, Bosques, $\mathrm{CO}_{2}$, Empresas, Energía/Población, GEI/Energía, GEI/Producto, Glaciares, Hechos/Población, Información, Litros, Madera, Organizaciones, Ozono $\left(\mathrm{O}_{3}\right)$, Plazas, Población, Residuos, Residuos/Población, Riego/Usuario, Superficie, Viajeros.

- Relevancia o Pertinencia del Indicador para el Desarrollo Sostenible: Este campo cualitativo contuvo la relevancia en el caso de la selección.

\footnotetext{
${ }^{8}$ Se trata de indicadores de tercera prioridad a construir, dentro del amplio espectro de indicadores que se sugiere. Sin embargo, ellos resultan en algunos casos de difícil elaboración, debido a la escasa disponibilidad de fuentes de datos. De todas maneras, se considera que ellos contribuirían a optimizar el funcionamiento del sistema de información estadística con vistas al monitoreo y seguimiento de las políticas de desarrollo sostenible para en el nivel local (Definición adaptada a partir de UNFPA, 2014, p. 38).
} 
- Motivo de la no selección: Es el campo que identifica las dificultades para su inclusión o las decisiones teóricas para la no selección.

- Fuente: se estableció en siglas, por ejemplo el Censo Nacional de Población Hogares y Viviendas (CNPHV).

- Observaciones: a esta condición se agregó un color distinguiendo la categoría 1a (verde) 1 b (rojo) 2 (naranja) y 3 (amarillo)

Una vez revisados los indicadores por medio de la grilla de evaluación, se elaboró, con cada indicador seleccionado como imprescindible (1a y $1 \mathrm{~b}$ ), una ficha metodológica con toda la metadata en la que se destaca la relevancia y pertinencia del indicador en el sistema, la frecuencia, la fuente y las definiciones operativas y conceptuales de los mismos. Para la confección de la misma se siguieron los campos sintetizados en la Tabla 2 elaborada a partir de las perspectivas teóricas y metodológicas de Rayen Quiroga Martínez (2009, p. 68-69).

Tabla 3. Contenidos de las fichas metodológicas

\begin{tabular}{|c|c|}
\hline Nombre del Indicador & $\begin{array}{l}\text { Se debe poner un nombre lo más claro, conciso y amistoso al usuario, que defina } \\
\text { exactamente lo que muestra el indicador. }\end{array}$ \\
\hline $\begin{array}{l}\text { Breve descripción del } \\
\text { Indicador }\end{array}$ & $\begin{array}{l}\text { Se debe realizar una descripción corta de lo que muestra el indicador, sobre todo } \\
\text { cuando éste recibe un nombre más bien científico o técnico; utilizando un lenguaje } \\
\text { claro y simple que termine por ubicar al usuario respecto del indicador en cuestión. }\end{array}$ \\
\hline $\begin{array}{l}\text { Relevancia o } \\
\text { Pertinencia del } \\
\text { Indicador }\end{array}$ & $\begin{array}{l}\text { Se debe especificar la importancia que tiene el indicador propuesto en la evaluación } \\
\text { sobre el medio ambiente o respecto de la sostenibilidad. }\end{array}$ \\
\hline $\begin{array}{l}\text { Alcance (qué mide el } \\
\text { indicador) }\end{array}$ & $\begin{array}{l}\text { Se debe especificar que dinámicas son las que "captura" o "muestra" el indicador. } \\
\text { Mostrar exactamente qué cosas nos estaría diciendo el indicador en cuestión. }\end{array}$ \\
\hline $\begin{array}{l}\text { Limitaciones del } \\
\text { indicador }\end{array}$ & $\begin{array}{l}\text { Se debe aclarar que otras dimensiones y dinámicas no pueden ser capturadas o vistas } \\
\text { a partir del indicador, y que el usuario menos experto pudiese dar por contenidas. }\end{array}$ \\
\hline $\begin{array}{l}\text { Fórmula y definición de } \\
\text { las variables que } \\
\text { componen el indicador }\end{array}$ & $\begin{array}{l}\text { Debe especificar las operaciones y procesamientos de las variables que son } \\
\text { necesarios para obtener el valor del indicador en cada punto de observación } \\
\text { (territorial, histórica, etc.). Así, debe quedar perfectamente estipulada la unidad de } \\
\text { medida en que se expresará el indicador. } \\
\text { Cada una de las variables que componen el indicador debe ser definida con detalle, } \\
\text { de forma que no quede lugar a "interpretaciones". Se utiliza comúnmente adoptar la } \\
\text { definición de la institución que produce el dato. }\end{array}$ \\
\hline Fuente de los Datos & $\begin{array}{l}\text { La fuente del dato debe quedar estipulada para cada una de las variables, en forma } \\
\text { detallada: especificar no sólo la institución, sino también el departamento u oficina, } \\
\text { y/o la publicación física o electrónica donde se encuentra disponible (si } \\
\text { correspondiera) y el nombre y correo electrónico de contacto de la persona a cargo. }\end{array}$ \\
\hline Disponibilidad del dato & $\begin{array}{l}\text { La disponibilidad de los datos se refiere a que tan fácil o difícil es el acceso } \\
\text { sistemático al dato, más allá de que formalmente se encuentre producido. }\end{array}$ \\
\hline Periodicidad de los & Se debe especificar la periodicidad para cada variable que compone el indicador. \\
\hline Datos & Esta se entiende como el período de tiempo en que se actualiza el dato. \\
\hline Resultados & $\begin{array}{l}\text { Gráfico o representación, con frase de tendencia. Elaborar una representación, } \\
\text { idealmente gráfica, del indicador. A menudo se descubren errores y potencias no } \\
\text { previstas desde el análisis de los gráficos (más que a partir de tablas). Probar con } \\
\text { varios esquemas o tipos de gráficos hasta ver el resultado óptimo de lo que se quiere } \\
\text { mostrar con el indicador en cuestión. Elaborar una frase de tendencia que podría } \\
\text { titular el indicador completo, o bien sólo el gráfico. }\end{array}$ \\
\hline
\end{tabular}

Fuente: Elaboración propia en base a Quiroga Martínez (2009, p. 68-69)

Cabe destacar que la intención de un sistema de información que comprenda y monitoree el desarrollo local sostenible es llegar al nivel de desagregación de información necesario más pequeño, aunque no siempre este es el disponible, en este sentido la fuentes de datos inducen la selección de las unidades, es decir si el mismo se encuentra disponible para el nivel 
administrativo-político de departamento ${ }^{9}$, como es el caso de las Estadísticas Vitales, o para el nivel de localidad ${ }^{10}$, como puede darse en los Censos Nacionales de Población, Hogares y Viviendas, podremos disponer de mayor desagregación.

\subsection{Las características de Tierra del Fuego}

La provincia de Tierra del Fuego, Antártida e Islas del Atlántico Sur está ubicada en el extremo más austral de la República Argentina. Se encuentra conformada por tres partes bien definidas: la que se compone de la Isla Grande y el Archipiélago Fueguino (Isla de los Estados, Gable, Bridges, etc.), las Islas del Atlántico Sur (Malvinas, Georgias del Sur, Sandwich del Sur e Islas Orcadas del Sur) y finalmente la Antártida Argentina. Esto brinda una superficie total de $1.002 .445 \mathrm{~km}^{2}$.

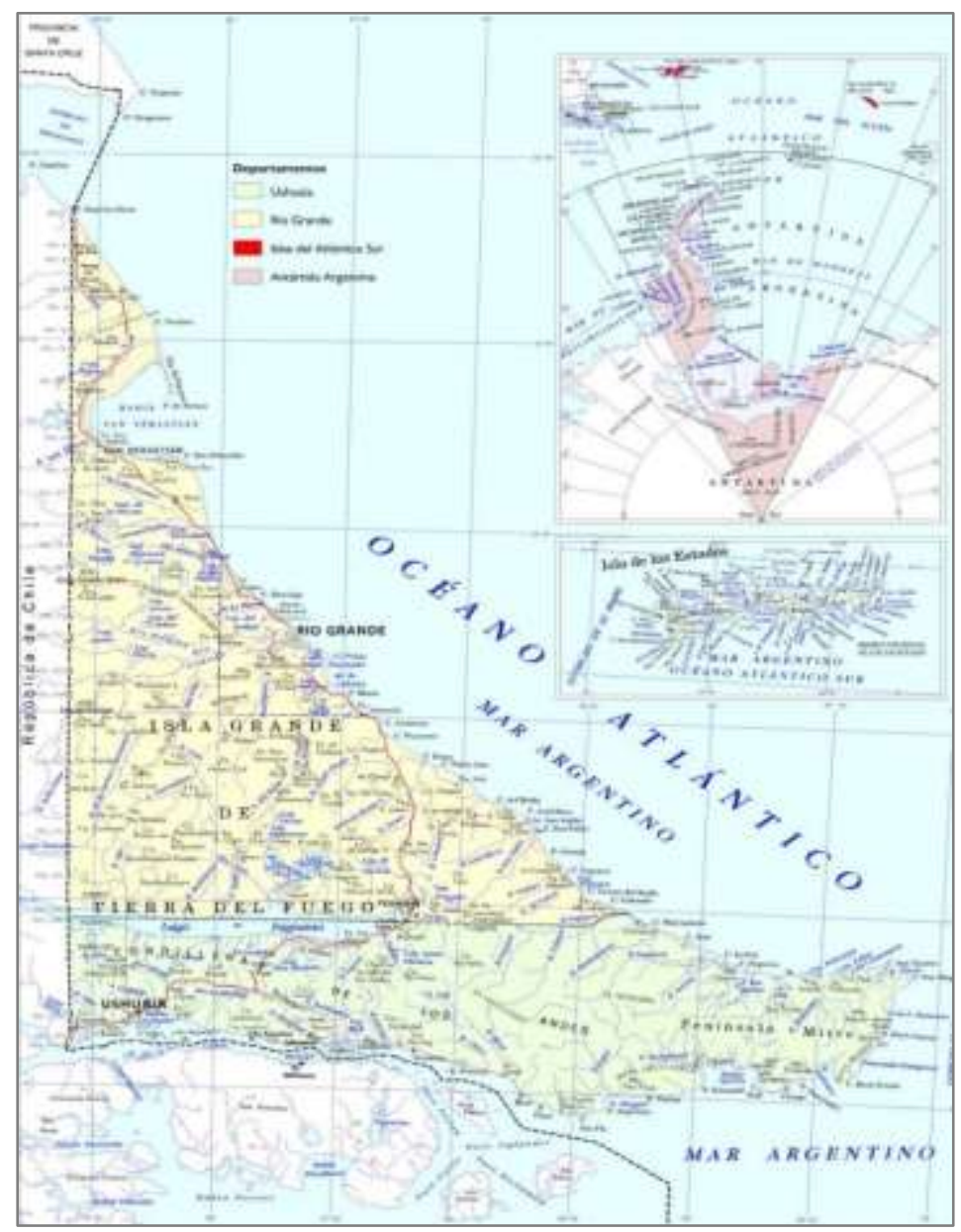

Mapa 1. División Política de la Provincia de Tierra del Fuego, Antártida e Islas del Atlántico Sur. Año 2002 Fuente: Atlas. Subsecretaría de Planeamiento - Gobierno de la Provincia de Tierra del Fuego, Antártida e Islas del Atlántico Sur.

\footnotetext{
9 Los departamentos, partidos o comunas son divisiones jurídico-administrativas, las dos últimas correspondientes a la provincia de Buenos Aires y a la ciudad homónima, que en algunos casos no guardan correspondencia alguna con la configuración municipal (o de los gobiernos locales) y hasta se interponen en la división del territorio. Igualmente la de departamento o partido es una de las divisiones territoriales más antiguas sobre las que se presenta información (INDEC-SIEL 2006)

${ }^{10}$ Para el INDEC "el concepto de localidad es un concepto censal, de carácter físico. Una localidad es el área comprendida por una envolvente que rodea, en toda su extensión, una mancha urbana continua. En el tiempo que transcurre entre un censo y otro, esta área puede verse modificada o no. Generalmente tiende a expandirse, como consecuencia de la construcción de nuevos barrios o grupos de viviendas en los alrededores" (INDEC-PRINEM, 1999)
} 
La región de la Isla Grande y el Archipiélago Fueguino se componen de dos departamentos, Río Grande con $12.181 \mathrm{~km}^{2}$ y Ushuaia con $9.390 \mathrm{~km}^{2}$, lo que significa una superficie total $21.571 \mathrm{~km}^{2}$. Esta es la superficie sobre la que se presentan las zonas urbanas más importantes y casi todas las actividades productivas. Por lo que a lo largo del presente documento entenderemos por Tierra del Fuego solamente a la porción comprendida por esta región.

A su vez, el área cuenta con tres localidades y municipios principales (Río Grande, Tolhuin y Ushuaia) que acumulan toda la población urbana y un 98,9\% de los 127.205 personas censadas en el 2010 en toda la provincia, siendo la participación de Tolhuin sólo el 2\%. En este sentido las dos principales ciudades muestran una especial importancia en la dinámica provincial.

Su localización en el extremo sur le brinda una característica en términos climáticos que establecen temperaturas medias anuales para la ciudad de Ushuaia de $5,3^{\circ} \mathrm{C}$ y para Río Grande de $5,5^{\circ} \mathrm{C}$, con una amplitud que no resulta muy grande, con una máxima promedio de $9,2^{\circ} \mathrm{C}$ en el mes de Enero y $1,1^{\circ} \mathrm{C}$ para el mes de Julio. Este fenómeno se basa en las contribuciones que hacen las corrientes marinas de Malvinas y Cabo de Hornos (Livraghi, 2011, p. 29). Por otra parte no existen períodos libres de heladas, lo que limita el éxito de los cultivos.

Tierra del Fuego presenta precipitaciones asociadas más a los desplazamientos de los centros de alta y baja presión y menos a los fenómenos convectivos. Los mayores valores los presenta la Isla de los Estados con $750 \mathrm{~mm}$ anuales, en las Costas del Beagle (Ushuaia) los registros se acercan a los $500 \mathrm{~mm}$ anuales y en el norte de la Isla (Cabo Espíritu Santo) los valores apenas alcanzan los $280 \mathrm{~mm}$. Las lluvias se distribuyen de forma homogénea a lo largo del año, aunque para Río Grande hay una disminución entre Septiembre y Octubre. En el caso de Ushuaia la precipitación nival es un componente significativo entre mayo y septiembre.

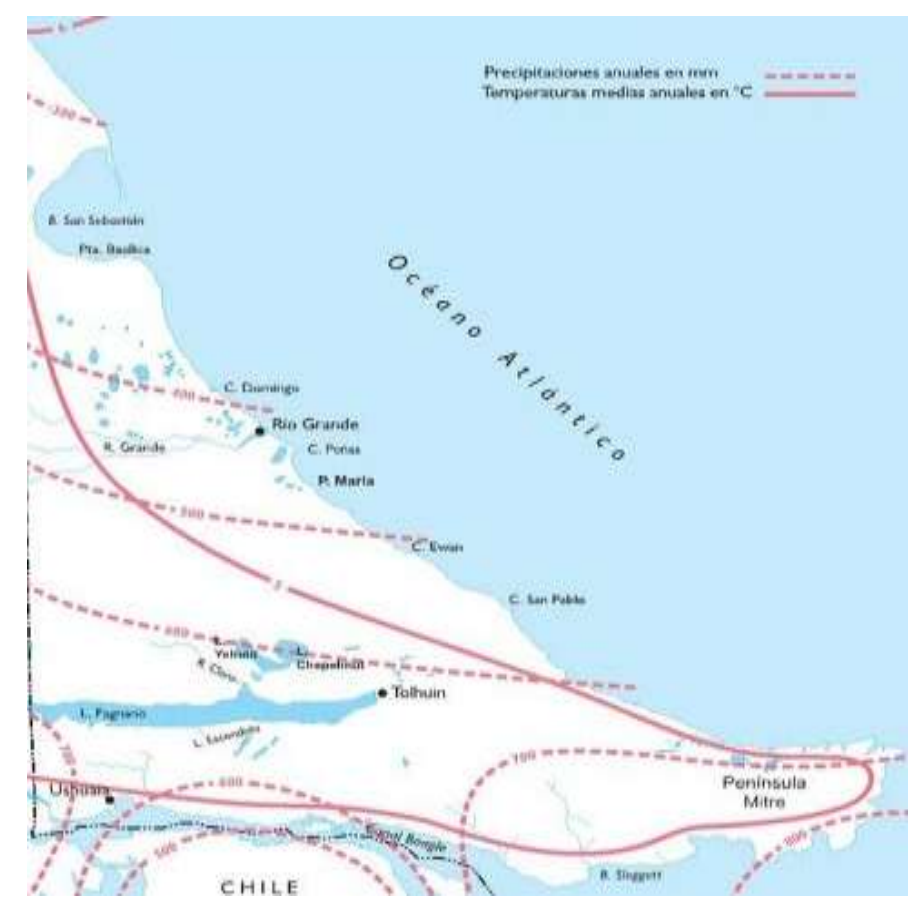

Mapa 2. Temperaturas y precipitaciones de la Isla Grande de la Provincia de Tierra del Fuego, Antártida e Islas del Atlántico Sur. Año 2002. Fuente: Atlas. Subsecretaría de Planeamiento - Gobierno de la Provincia de Tierra del Fuego, Antártida e Islas del Atlántico Sur. 
Los vientos proceden generalmente del Oeste. Se expresan con un promedio anual de $14 \mathrm{~km} / \mathrm{h}$ en Ushuaia y $23 \mathrm{~km} / \mathrm{h}$ en Río Grande, aunque pueden presentar máximas promedios de 130 $\mathrm{km} / \mathrm{h}$, siendo noviembre el mes más ventoso.

Tal como se observa en el mapa 1 la provincia cuenta con una importante red hídrica, favorecida principalmente por la distribución uniforme de las precipitaciones. Cuenta con tres vertientes principales: la del Atlántico, la del Pacífico y la del Canal de Beagle. Por otro lado existen diferentes cuencas (de la Estepa, de la Cordillera, Englazadas, de Transición, de Turberas) que presentan diferentes lugares de almacenamiento, tales como lagunas, lagos, glaciares, acumulaciones níveas, turbales, etc. (Livraghi, 2011, p. 34)

De esta forma encontramos tres áreas del ambiente fueguino, la que recorre la Cordillera desde la Península Mitre al este hasta el límite con la República de Chile, al sur con el Canal de Beagle y al Norte levemente sobre el Lago Fagnano. Lugar donde comienza el Ecotono o Parque Fueguino, una región de transición entre la montaña y bosque andino patagónico y la Estepa Magallánica, caracterizada por presentar pastos y vegetación baja, con escasa participación de bosques, paisaje típico de casi toda la estepa patagónica.

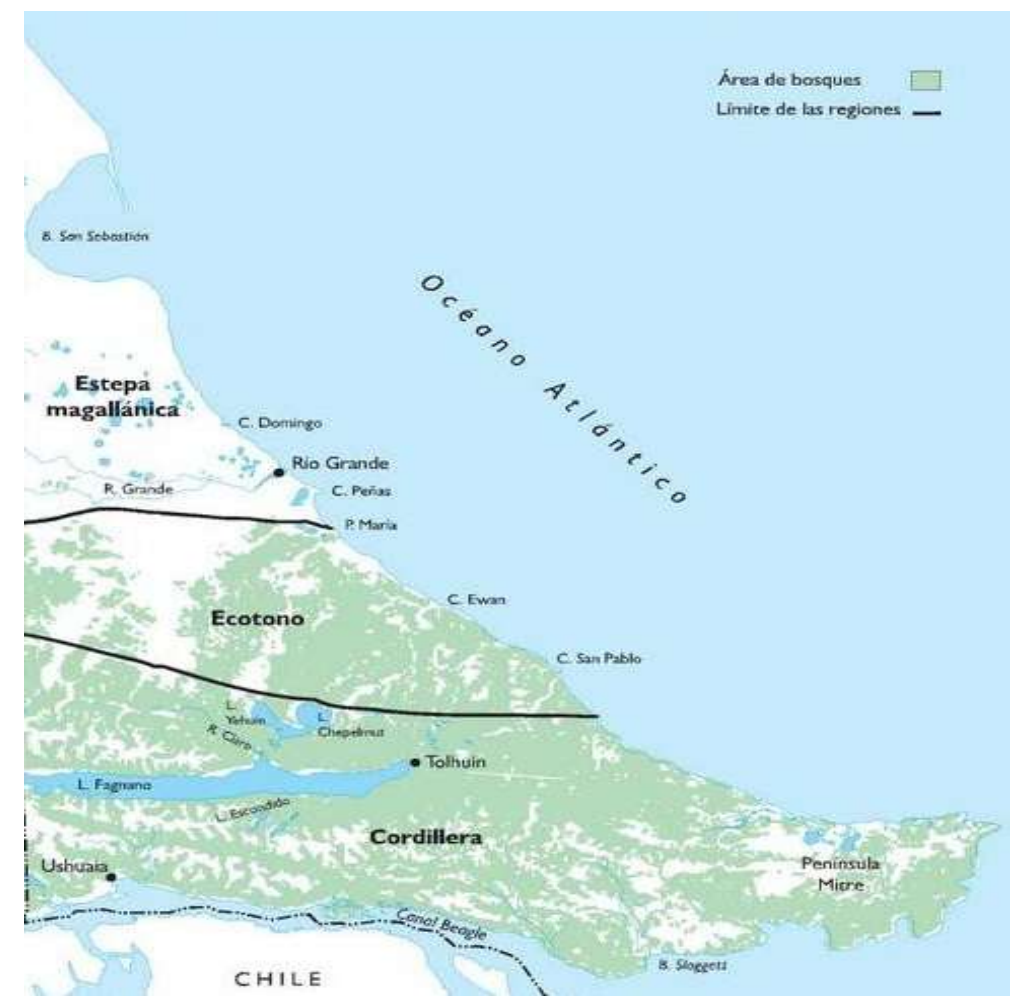

Mapa 3. Áreas biogeográficas de la Isla Grande de la Provincia de Tierra del Fuego, Antártida e Islas del Atlántico Sur. Año 2002. Fuente: Atlas. Subsecretaría de Planeamiento - Gobierno de la Provincia de Tierra del Fuego, Antártida e Islas del Atlántico Sur.

Los bosques presentes en el Ecotono y la Cordillera cuentan con una superficie total de $712.153 \mathrm{ha}$, en las que se encuentran tres especies de Nothofagus, la pumilio (lenga), la antártica (ñire) y la betuloides (guindo), que a diferencia de las anteriores su follaje es perenne.

En términos de la dinámica económica relacionada a la explotación de recursos naturales (Mastroscello 2007), es significativo mencionar que la provincia cuenta con una importante 
explotación hidrocarburífera en la región norte de la Isla Grande desde inicios de la década del sesenta (Carpinetti 2003). La actividad forestal presenta casi un siglo de antigüedad en la Cordillera, aunque en la actualidad se ha trasladado exclusivamente a la región del Ecotono (Romano 2015). Finalmente es destacable la producción pesquera especialmente en el Canal de Beagle, pero también la pesca de altura desarrollada en el Océano Atlántico, aunque esta se presenta como un recurso de dominio nacional y no provincial.

La dinámica social (Hermida 2017) presenta un impacto ambiental directo en las áreas urbanas de las tres localidades de la provincia, especialmente en las dos más densamente pobladas, Ushuaia y Río Grande. Dado que se tratan de ciudades intermedias de rápida expansión producto de los flujos migratorios (Hermida et al 2016) presentan tensiones en el plano habitacional (Pérez y Martinez 2014) que se traducen en problemas de planificación urbano-ambiental, especialmente vinculadas a la cobertura de servicios urbanos de saneamiento.

\section{RESULTADOS OBTENIDOS}

A continuación se presenta la aplicación del modelo teórico y metodológico exhibido en el segundo apartado del presente trabajo. Así se aprecian los resultados de la investigación, y la selección de los indicadores representativos de la dimensión ambiental y sus relaciones con otras dimensiones para la Provincia de Tierra del Fuego.

\subsection{Hacia un sistema de información}

Tal como se observó anteriormente, un sistema de información estadística requiere de la selección de indicadores relevados por diversos organismos públicos y privados. Estas fuentes de datos e información no siempre son especializadas, una parte de la misma suele estar basada en registros administrativos, los que requieren un tratamiento específico que consolide la información de forma confiable, oportuna, válida y que sea capaz de cumplir los criterios de calidad (Hermida 2009, Hermida 2012).

Cuando las fuentes de información son generadas por organismos especializados en la estadística pública, dichos requisitos suelen estar cubiertos ${ }^{11}$, sin embargo el análisis de las fuentes siempre es una condición obligada en el desarrollo de un sistema de información.

En este sentido hemos evaluado, por medio de la grilla de evaluación descripta al inicio del presente documento un total de 113 indicadores para todo el sistema, y 38 de la dimensión ambiental, teniendo en cuenta los específicos del subsistema ambiental y sus relaciones (Hermida, 2016). Aquellos que se encuentren incluidos en los dos primeros segmentos (1a: Imprescindibles con información disponible y $1 \mathrm{~b}$ : Imprescindibles que se requieren construir en el mediano plazo) son los indicadores seleccionados para la primera etapa del sistema, las restantes categorías incluyen aquella información que se sugiere adicionar al sistema con la paulatina mejora en la calidad y disponibilidad de los datos.

Tabla 4. Evaluación de los indicadores según sub sistema e interrelación.

\footnotetext{
${ }^{11}$ Si bien los organismos que conforman el Sistema Estadístico Nacional (INDEC, DEIS, DiNIECE, Direcciones Provinciales de Estadística, etc.) suelen producir la información siguiendo rigurosos estándares de calidad, sin embargo ellos pueden también ser producto de manipulaciones, basadas en pujas políticas, económicas, o de intereses particulares, que generen perjudicar la calidad, y primordialmente, la credibilidad en la información. Es por este motivo que se debe someter a revisión los datos e indicadores producidos por dichos organismos, observando la oportunidad de los mismos en el marco de un sistema de información.
} 


\begin{tabular}{|c|c|c|c|c|c|c|c|c|}
\hline & $\begin{array}{l}\text { Indica- } \\
\text { dores } \\
\text { incluidos } \\
\text { en } \\
\text { niveles } \\
\text { 1a y } 1 \mathrm{~b}\end{array}$ & $\begin{array}{l}\text { Indica- } \\
\text { dores } \\
\text { incluidos } \\
\text { en } \\
\text { niveles } 2 \\
\text { y } 3\end{array}$ & $\begin{array}{l}\text { Indica- } \\
\text { dores no } \\
\text { incluidos }\end{array}$ & $\begin{array}{c}\text { Indicado } \\
\text { res } \\
\text { evaluado } \\
\text { s para el } \\
\text { SIEDLS } \\
\text {-TDF }\end{array}$ & $\begin{array}{c}\text { Indicado } \\
\text { res } \\
\text { presente } \\
\text { s en el } \\
\text { SIDSA } \\
\text { al } 2014\end{array}$ & $\begin{array}{c}\text { Indicado } \\
\text { res } \\
\text { seleccio } \\
\text { nados ya } \\
\text { presente } \\
\text { s en el } \\
\text { SIDSA } \\
\end{array}$ & $\begin{array}{l}\text { Indicado } \\
\text { res } \\
\text { elegidos } \\
\text { para el } \\
\text { SIEDLS } \\
\text {-TDF }\end{array}$ & $\begin{array}{c}\text { Total de } \\
\text { indicado } \\
\text { res } \\
\text { analizad } \\
\text { os }\end{array}$ \\
\hline Total de indicadores & 42 & 41 & 30 & 23 & 90 & 28 & 14 & 113 \\
\hline Subsistema Social & 10 & 10 & 3 & 4 & 19 & 7 & 3 & 23 \\
\hline $\begin{array}{l}\text { Subsistema } \\
\text { Ambiental }\end{array}$ & 7 & 2 & 5 & 4 & 10 & 3 & 4 & 14 \\
\hline $\begin{array}{l}\text { Subsistema } \\
\text { Económico }\end{array}$ & 6 & 6 & 0 & 5 & 7 & 4 & 2 & 12 \\
\hline $\begin{array}{l}\text { Subsistema } \\
\text { Institucional }\end{array}$ & 3 & 7 & 5 & 4 & 11 & 1 & 2 & 15 \\
\hline $\begin{array}{l}\text { Total de indicadores } \\
\text { de relación }\end{array}$ & 14 & 12 & 17 & 5 & 38 & 12 & 2 & 43 \\
\hline $\begin{array}{l}\text { Interrelación Local- } \\
\text { Global }\end{array}$ & 2 & 3 & 4 & 2 & 7 & 2 & 0 & 9 \\
\hline $\begin{array}{l}\text { Interrelación } \\
\text { Económico- } \\
\text { Ambiental }\end{array}$ & 3 & 4 & 10 & 3 & 14 & 1 & 2 & 17 \\
\hline $\begin{array}{l}\text { Interrelación } \\
\text { Ambiental-Social }\end{array}$ & 2 & 2 & 0 & 0 & 4 & 2 & 0 & 4 \\
\hline $\begin{array}{l}\text { Interrelación } \\
\text { Económico-Social }\end{array}$ & 2 & 0 & 0 & 0 & 2 & 2 & 0 & 2 \\
\hline $\begin{array}{l}\text { Interrelación } \\
\text { Institucional- } \\
\text { Económico }\end{array}$ & 1 & 1 & 2 & 0 & 4 & 1 & 0 & 4 \\
\hline $\begin{array}{l}\text { Interrelación } \\
\text { Institucional-Social }\end{array}$ & 2 & 2 & 0 & 0 & 4 & 2 & 0 & 4 \\
\hline $\begin{array}{l}\text { Interrelación } \\
\text { Institucional- } \\
\text { Ambiental }\end{array}$ & 2 & 0 & 1 & 0 & 3 & 2 & 0 & 3 \\
\hline $\begin{array}{l}\text { Intensidad o } \\
\text { Eficiencia }\end{array}$ & 2 & 4 & 0 & 1 & 5 & 1 & 1 & 6 \\
\hline
\end{tabular}

Fuente: Elaboración propia en base a análisis de indicadores SIDSA 2014 y entrevistas a informantes clave 2013 a 2014

Este primer grupo de indicadores imprescindibles está conformado por 42 indicadores, 28 que son comparables con el Sistema de Información para el Desarrollo Sostenible de Argentina (SIDSA) presente a nivel nacional, y 14 que permiten observar la especificidad de la provincia en el Sistema de Información Estadística para el Desarrollo Local Sostenible de Tierra del Fuego (SIEDLS-TDF) que fue objeto de nuestra investigación.

Cabe destacar que uno de los requisitos planteados por Rayen Quiroga Martínez (2009) establece un número acotado para todo el sistema de indicadores, cercano a 30. En este marco se decidió establecer un sistema algo más concentrado que el existente a nivel nacional, para ello se estipuló que a los 42 indicadores iniciales, un número similar podrían ser incluidos en una segunda y tercera etapa, cuando la disponibilidad de la información y pertinencia lo permita. 


\subsection{Los indicadores ambientales para el desarrollo sostenible}

Si bien para la evaluación y selección de indicadores de todas las dimensiones se utilizaron entrevistas a informantes claves, la ambiental fue la que presentó mayor presencia de aplicación de dicha metodología cualitativa. Esto se debe a tres cuestiones, por un lado a la gran distancia disciplinar existente respecto de las restantes dimensiones, por otro a la falta de organismos rectores que contengan gran parte de los indicadores, y finalmente y quizá la más importante, por las diferencias que presenta el ambiente local respecto de la heterogeneidad nacional e internacional.

Esta dimensión, de las cuatro que conforman el desarrollo sostenible, es la que mayor cantidad de indicadores específicos para Tierra del Fuego presenta y con ello, la mayor diversidad de fuentes de información. El Instituto Provincial de Análisis e Investigación, Estadística y Censos (IPIEC), organismo rector del Sistema Estadístico Provincial, aportó datos sólo para la superficie de la provincia. Los restantes indicadores tuvieron por fuente local a la Secretaría de Desarrollo Sustentable y Ambiente de la provincia, con dos direcciones, la de Bosques y la de Recursos Hídricos. La información referente a hidrocarburos tuvo por organismo productor de información a la Secretaría de Energía de la Nación. Si bien la provincia cuenta con datos en la Secretaría de Hidrocarburos, estos no circulan de forma abierta sino bajo pedido, por otra parte no se encuentran consistidos con los datos a nivel nacional y con un buen nivel de cálculo, hecho que hizo considerar a la fuente nacional como la mejor opción.

Finalmente el último organismo a considerar fue el Centro Austral de Investigaciones Científicas (CADIC), Consejo Nacional de Investigaciones (CONICET). Si bien los investigadores utilizan y elaboran los indicadores de fuentes diversas, la presentación de los datos resumidos, sintéticos y confiables fue eje de evaluación en las entrevistas a los informantes clave que se desempeñan en el centro de investigaciones.

Para la dimensión ambiental se analizó un total de 14 indicadores, siendo 10 los existentes en el modelo nacional (SIDSA) y 4 los propuestos por los informantes clave para el sistema provincial y que fueron incluidos en el mismo en la primera etapa.

\begin{tabular}{|c|c|c|}
\hline $\begin{array}{c}\text { Nombre del } \\
\text { indicador }\end{array}$ & Breve descripción & $\begin{array}{c}\text { Fuente y organismo productor de } \\
\text { datos }\end{array}$ \\
\hline $\begin{array}{l}\text { Superficie de la } \\
\text { Provincia de Tierra } \\
\text { del Fuego }\end{array}$ & $\begin{array}{l}\text { Área o extensión del territorio provincial, } \\
\text { departamental y municipal expresada en } \\
\text { kilómetros cuadrados }\end{array}$ & $\begin{array}{l}\text { Dirección General de Estadísticas y } \\
\text { Censos (DGEyC) en base a INDEC, } \\
\text { Censo Nacional de Población, } \\
\text { Hogares y Viviendas } 2010\end{array}$ \\
\hline $\begin{array}{l}\text { Balance de masa } \\
\text { del Glaciar Martial }\end{array}$ & $\begin{array}{l}\text { Es la diferencia entre la cantidad de hielo } \\
\text { depositada en la zona de acumulación y la } \\
\text { cantidad de hielo perdida en la zona de } \\
\text { ablación durante un periodo de tiempo } \\
\text { determinado (normalmente se considera un año } \\
\text { hidrológico, o sea desde el inicio del invierno } \\
\text { hasta el final del verano) es un indicador del } \\
\text { "estado de salud" o "balance de masa" del } \\
\text { glaciar. }\end{array}$ & $\begin{array}{l}\text { Jorge Strelin y Rodolfo Iturraspe, } \\
\text { Instituto Antártico Argentino y } \\
\text { Centro Austral de Investigaciones } \\
\text { Científicas (CADIC). Dirección } \\
\text { Provincial de Recursos Hídricos }\end{array}$ \\
\hline $\begin{array}{l}\text { Tasa de } \\
\text { aprovechamiento } \\
\text { en superficie y } \\
\text { volumen forestal }\end{array}$ & $\begin{array}{l}\text { Es la relación entre los metros cúbicos de } \\
\text { madera aprovechada y las hectáreas destinadas } \\
\text { a la explotación forestal. }\end{array}$ & $\begin{array}{l}\text { Dirección General de Bosques. } \\
\text { Secretaría de Desarrollo Sustentable y } \\
\text { Ambiente. Gob. de Tierra del Fuego }\end{array}$ \\
\hline
\end{tabular}




\begin{tabular}{|c|c|c|}
\hline $\begin{array}{l}\text { Nombre del } \\
\text { indicador }\end{array}$ & Breve descripción & $\begin{array}{c}\text { Fuente y organismo productor de } \\
\text { datos }\end{array}$ \\
\hline $\begin{array}{l}\text { Captura por unidad } \\
\text { de esfuerzo de la } \\
\text { Centolla (CPUE } \\
\text { media) }\end{array}$ & $\begin{array}{l}\text { La cantidad de capturas que se logran por } \\
\text { unidad de arte de pesca; por ejemplo, el } \\
\text { número de centollas por trampa-mes es una } \\
\text { forma de expresar la CPUE. }\end{array}$ & $\begin{array}{l}\text { Gustavo A. Lovrich y Federico } \\
\text { Tapella. Centro Austral de } \\
\text { Investigaciones Científicas (CADIC), } \\
\text { Consejo Nacional de Investigaciones } \\
\text { (CONICET) }\end{array}$ \\
\hline
\end{tabular}

Dado que los anteriores no se encontraban en el modelo nacional, se seleccionaron para la primera etapa (imprescindibles 1a y 1b) 3 indicadores ya existentes en el SIDSA. Todo ello siempre a partir de aplicar los criterios de cobertura y calidad de la información atinentes al desarrollo metodológico pre-establecido.

\begin{tabular}{|c|c|c|}
\hline $\begin{array}{c}\text { Nombre del } \\
\text { indicador }\end{array}$ & Breve descripción & $\begin{array}{c}\begin{array}{c}\text { Fuente y organismo productor de } \\
\text { datos }\end{array} \\
\end{array}$ \\
\hline $\begin{array}{l}\text { Reservas declaradas } \\
\text { comprobadas más } \\
50 \% \text { de las reservas } \\
\text { probables de } \\
\text { hidrocarburos } \\
\text { (petróleo y gas) }\end{array}$ & $\begin{array}{l}\text { Totaliza las reservas de hidrocarburos (petróleo } \\
\text { y gas) comprobadas (extraídas y remanentes) y } \\
\text { suma un } 50 \% \text { de las reservas probables, año a } \\
\text { año y para todo el país, permitiendo una } \\
\text { estimación cercana a la situación real. La } \\
\text { elección del } 50 \% \text { de probables se corresponde al } \\
\text { valor elegido a nivel mundial. }\end{array}$ & $\begin{array}{l}\text { Boletín anual de reservas, Secretaria } \\
\text { de Energía. }\end{array}$ \\
\hline $\begin{array}{l}\text { Horizonte de } \\
\text { reservas de } \\
\text { hidrocarburos } \\
\text { (petróleo y gas) }\end{array}$ & $\begin{array}{l}\text { Vincula las reservas comprobadas de } \\
\text { hidrocarburos del país (petróleo y gas), con el } \\
\text { volumen de producción correspondiente a un } \\
\text { año dado }\end{array}$ & $\begin{array}{l}\text { Boletín anual de reservas, Secretaria } \\
\text { de Energía. }\end{array}$ \\
\hline $\begin{array}{l}\text { Porcentaje de la } \\
\text { superficie cubierta } \\
\text { de bosques nativos }\end{array}$ & $\begin{array}{l}\text { Relaciona la superficie de bosques nativo y la } \\
\text { superficie del territorio fueguino. }\end{array}$ & $\begin{array}{l}\text { Informe Regional de Bosque Andino } \\
\text { Patagónico, Dirección Nacional de } \\
\text { Recursos Naturales y Conservación } \\
\text { de la Biodiversidad, Dirección de } \\
\text { Bosques. Secretaría de Ambiente y } \\
\text { Desarrollo Sustentable. }\end{array}$ \\
\hline
\end{tabular}

De todos los indicadores evaluados sólo 5 (Porcentaje de hectáreas erosionadas por tipo de erosión, Participación de fuentes renovables en la Oferta Total de Energía Primaria, Evolución de biomasa y biomasa reproductiva: Merluza común, Evolución de biomasa y biomasa reproductiva: merluza de cola y Evolución de biomasa y biomasa reproductiva: anchoita bonaerense) no fueron seleccionados para formar parte del sistema en ninguno de los tres momentos, esto se debe a que se carece de incidencia del evento en el territorio, principalmente por características locales del medio ambiente, cuestión por la cual es imposible su cálculo en el futuro. Sólo 2 indicadores quedaron estipulados para una segunda o tercera etapa de desarrollo del sistema: Superficie de bosque nativo y Disponibilidad hídrica superficial por cuenca.

\subsection{Los indicadores de relación con otras dimensiones}

Tal como se observó anteriormente el sistema establece indicadores que permitan medir la relación entre los cuatro sub sistemas. Dado que el objeto del presente trabajo es la dimensión ambiental, hemos priorizado la presentación de las interrelaciones de los restantes subsistemas con la dimensión en análisis, de esta forma se excluyeron de este artículo los indicadores que miden la interrelación económico-social, la institucional-social y la institucional-económico. Se presentan los resultados de las siguientes: 
- Interrelación Económico-Ambiental

- Interrelación Ambiental-Social

- Interrelación Institucional-Ambiental

A su vez se incluyó la presentación de la Interrelación Local/Global debido a que expresa la relación del sistema con el resto del mundo y a la naturaleza de los indicadores propuestos por el sistema nacional. Como se puede apreciar en los apartados anteriores el sistema de desarrollo local sostenible no es cerrado, sino que genera interacciones con el "afuera". Para su medición se analizó un total de 9 indicadores, $7^{12}$ ya presentes en el SIDSA y 2 evaluados a nivel local (Medición de la columna total de ozono, e Ingreso y egreso de viajeros). 3 Indicadores fueron evaluados para una segunda y tercer etapa, los dos locales antes nombrados y Comercio Exterior de Servicios Culturales que ya estaba presente en el SIDSA. Finalmente se seleccionaron como imprescindibles para la primera etapa dos indicadores comparables con el modelo nacional:

\begin{tabular}{|c|c|c|}
\hline $\begin{array}{l}\text { Nombre del } \\
\text { indicador }\end{array}$ & Breve descripción & $\begin{array}{l}\text { Fuente y organismo productor de } \\
\text { datos }\end{array}$ \\
\hline $\begin{array}{l}\text { Emisiones totales de } \\
\text { gases de efecto } \\
\text { invernadero por } \\
\text { sector }\end{array}$ & $\begin{array}{l}\text { Expresa a nivel provincial las emisiones totales } \\
\text { de los gases efecto invernadero (GEIs) } \\
\text { regulados por el Protocolo de Kyoto que } \\
\text { contribuyen al cambio climático global. Estos } \\
\text { gases son: dióxido de carbono (CO2), metano } \\
\text { (CH4), óxido nitroso (N2O), } \\
\text { Clorofluorocarbono (CFC), } \\
\text { Hidrofluorocarbono (HFC) y Hexafloruro de } \\
\text { Azufre (SF6). } \\
\text { Las emisiones totales se expresan desagregadas } \\
\text { por los sectores económicos, donde deberán } \\
\text { efectuarse reducciones. }\end{array}$ & $\begin{array}{l}\text { Secretaría de Ambiente y Desarrollo } \\
\text { Sustentable de la Nación. } \\
\text { Dirección de Cambio Climático }\end{array}$ \\
\hline $\begin{array}{l}\text { Emisiones totales de } \\
\text { dióxido de carbono } \\
(\mathrm{CO} 2) \text { por energía } \\
\text { eléctrica }\end{array}$ & $\begin{array}{l}\text { Existe una correlación directa entre el tipo de } \\
\text { combustible quemado y las emisiones emitidas, } \\
\text { al relacionarse con el factor de emisión de CO2 } \\
\text { para dicho combustible este indicador permite } \\
\text { cuantificar las emisiones originadas por la } \\
\text { generación eléctrica para todo el sistema } \\
\text { interconectado nacional (Mercado Eléctrico } \\
\text { Mayorista MEM) y Sistema Patagónico). Se } \\
\text { puede conocer adicionalmente la naturaleza y } \\
\text { calidad de los combustibles utilizados en el } \\
\text { proceso y la evolución del parque } \\
\text { termoeléctrico a lo largo del tiempo }\end{array}$ & $\begin{array}{l}\text { Secretaría de Ambiente y Desarrollo } \\
\text { Sustentable de la Nación. } \\
\text { Dirección de Cambio Climático }\end{array}$ \\
\hline
\end{tabular}

Ambos indicadores requirieron cálculos basados en datos de la Oficina del Cambio Climático de la Secretaría de Ambiente de la Nación, de la Secretaría de Energía de la Nación y de la Dirección Provincial de Energía y Cooperativa de Servicios Públicos de Río Grande.

La interrelación económica ambiental incluyó el análisis de 17 indicadores totales. $10^{13}$ de ellos no fueron incluidos por no contar con disponibilidad del dato para la provincia,

\footnotetext{
${ }^{12}$ Emisiones totales de gases de efecto invernadero por sector, Emisiones totales de dióxido de carbono $(\mathrm{CO} 2)$ por energía eléctrica, Consumo de clorofluorocarbonados (CFC), Consumo de Hidroclorofluorocarbonados (HCFC), Apertura comercial, Comercio Exterior de Servicios Culturales y Variación del índice de exportaciones e importaciones industriales según potencial contaminante

${ }^{13}$ Consumo aparente de fertilizantes, Volumen comercializado de plaguicidas, Cambios de uso de la tierra implantada, Variación porcentual en el uso de la tierra agrícola para los principales cultivos, Evolución de la superficie destinada a la producción de cereales y oleaginosas, Evolución de la producción de cereales y
} 
principalmente por estar relacionados con la producción agrícola de cereales y oleaginosas que en Tierra del Fuego no presenta incidencia.

Por otra parte 4 indicadores (Residuos sólidos urbanos recogidos por tipo de disposición, Variación del volumen físico de la producción industrial según potencial contaminante, Porcentaje de empresas que incorporaron medidas de gestión ambiental y Riego, utilización superficial o subterránea para la mejora de pastizales) se seleccionaron para una segunda o tercera etapa del sistema. Finalmente 3 indicadores, que se describen a continuación, fueron seleccionados para la primera etapa:

\begin{tabular}{lll}
\multicolumn{1}{c}{$\begin{array}{c}\text { Nombre del } \\
\text { indicador }\end{array}$} & \multicolumn{1}{c}{ Breve descripción } & $\begin{array}{c}\text { Fuente y organismo productor } \\
\text { de datos }\end{array}$ \\
\hline $\begin{array}{l}\text { Generación de } \\
\text { residuos sólidos } \\
\text { urbanos }\end{array}$ & $\begin{array}{l}\text { El indicador muestra la cantidad de residuos } \\
\text { sólidos urbanos (RSU) generados por habitante en } \\
\text { el transcurso de un año. }\end{array}$ & $\begin{array}{l}\text { Observatorio Estadístico del } \\
\text { Municipio de Río Grande y la } \\
\text { Dirección de Gestión Ambiental } \\
\text { de la Municipalidad de Ushuaia. }\end{array}$ \\
\hline $\begin{array}{l}\text { Porcentaje de } \\
\text { superficie implantada } \\
\text { con forraje anual o } \\
\text { perenne }\end{array}$ & $\begin{array}{l}\text { Es la relación entre la superficie total destinada a a producción agropecuaria, principalmente } \\
\text { ganadera, y la superficie efectivamente cultivada } \\
\text { con forraje. }\end{array}$ & $\begin{array}{l}\text { INDEC, Censo Nacional } \\
\text { Agropecuario }\end{array}$ \\
\hline $\begin{array}{l}\text { Volúmenes netos de } \\
\text { extracción de madera }\end{array}$ & $\begin{array}{l}\text { Es la relación entre los metros cúbicos de madera } \\
\text { aprovechada y las hectáreas destinadas a la } \\
\text { explotación forestal. }\end{array}$ & $\begin{array}{l}\text { Dirección General de Bosques. } \\
\text { Secretaría de Desarrollo } \\
\text { Sustentable y Ambiente. Gob. de } \\
\text { Tierra del Fuego }\end{array}$ \\
\hline
\end{tabular}

Los dos últimos son de índole local y las fuentes de los mismos son los Censos Nacionales Agropecuarios, la Encuesta Provincial Agropecuaria, el INTA y la Dirección de bosques de la provincia. El primero fue calculado en base a datos municipales, el Observatorio Estadístico del Municipio de Río Grande y la Dirección de Gestión Ambiental de la Municipalidad de Ushuaia.

En términos de la relación Ambiental - Social, la evaluación realizada en base a un total de 4 indicadores, 2 (Tasa de notificación cada 100.000 habitantes: diarrea menores de 5 años, cólera y fiebre tifoidea/paratifoidea y Tasa de notificación cada 100.000 habitantes: neumonía y enfermedades tipo influenza) fueron seleccionados para una segunda o tercera etapa y 2 fueron seleccionados como imprescindibles:

\begin{tabular}{lll}
\multicolumn{1}{c}{$\begin{array}{c}\text { Nombre del } \\
\text { indicador }\end{array}$} & \multicolumn{1}{c}{ Breve descripción } & \multicolumn{1}{c}{$\begin{array}{c}\text { Fuente y organismo } \\
\text { productor de datos }\end{array}$} \\
\hline $\begin{array}{l}\text { Porcentaje de la } \\
\text { población en } \\
\text { hogares con }\end{array}$ & $\begin{array}{l}\text { Cuantifica la proporción de la población total en hogares } \\
\text { que tienen acceso a agua segura por red pública. Se } \\
\text { incluyen los hogares en los que la procedencia del agua } \\
\text { (superficial, subterránea) para beber, para higiene } \\
\text { acceso a agua de } \\
\text { personal y para cocinar es por red pública por cañería } \\
\text { dentro de la vivienda, fuera de la vivienda pero dentro del } \\
\text { terreno y fuera del terreno (a través de grifos públicos). }\end{array}$ & $\begin{array}{l}\text { Censos Nacionales de } \\
\text { Instituto Nación, Hogares y Vivienal de }\end{array}$ \\
\hline $\begin{array}{l}\text { Porcentaje de la y Censos (INDEC) } \\
\text { población en } \\
\text { hogares con } \\
\text { acceso a } \\
\text { desagües }\end{array}$ & $\begin{array}{l}\text { Cuantifica la proporción de la población total en hogares } \\
\text { que cuentan con cobertura de servicio de desagües } \\
\text { cloacales }\end{array}$ & $\begin{array}{l}\text { Censos Nacionales de } \\
\text { Población, Hogares y Vivienda. } \\
\text { Instituto Nacional de }\end{array}$ \\
\hline
\end{tabular}

oleaginosas, Mapas incremento superficie destinada a cultivos extensivos años 1995/1996 y 2010/2011, Participación de fuentes renovables de energía en la generación eléctrica total, Producción de madera industrial y Producción de leña 
Ambos indicadores son comparables con el SIDSA y cuentan por fuente de datos los Censos Nacionales de Población Hogares y Viviendas del INDEC. En ambos casos, ellos debieron ser calculados a partir del manejo de paquetes estadísticos aplicados al efecto.

Finalmente la relación institucional ambiental presentó 3 indicadores evaluados, todos presentes en el SIDSA. Un indicador (Relación entre captura máxima permisible y desembarques. Merluza y anchoíta) no fue seleccionado por no contarse con las especies pesqueras en análisis. Dos indicadores fueron seleccionados como imprescindibles:

\begin{tabular}{|c|c|c|}
\hline $\begin{array}{l}\text { Nombre del } \\
\text { indicador }\end{array}$ & Breve descripción & $\begin{array}{c}\begin{array}{c}\text { Fuente y organismo productor de } \\
\text { datos }\end{array} \\
\end{array}$ \\
\hline $\begin{array}{l}\text { Gasto en ecología } \\
\text { y medio ambiente }\end{array}$ & $\begin{array}{l}\text { Cuantifica la superficie de las áreas terrestres } \\
\text { protegidas en relación a la superficie total del } \\
\text { país. }\end{array}$ & $\begin{array}{l}\text { De } 1991 \text { a } 2008 \text { Dirección Nacional de } \\
\text { Política Criminal - Ministerio de } \\
\text { Justicia, Seguridad y DD.HH, y de } \\
2009 \text { a } 2013 \text { Dirección General de } \\
\text { Estadística y Censos, en base a } \\
\text { Jefatura de Policía de la provincia de } \\
\text { Tierra del Fuego. Departamento de } \\
\text { Asuntos Judiciales. }\end{array}$ \\
\hline $\begin{array}{l}\text { Áreas terrestres } \\
\text { protegidas como } \\
\text { porcentaje del total }\end{array}$ & $\begin{array}{l}\text { El gasto público provincial en ecología y medio } \\
\text { ambiente representa las erogaciones del sector } \\
\text { público no financiero a nivel provincial en la } \\
\text { protección del ambiente, en relación a la } \\
\text { población. }\end{array}$ & $\begin{array}{l}\text { Dirección General de Presupuesto del } \\
\text { Gobierno de la Provincia de Tierra del } \\
\text { Fuego }\end{array}$ \\
\hline
\end{tabular}

El primero fue calculado con datos de la Dirección General de Presupuesto de la Provincia y el segundo con información del Sistema Federal de Áreas Protegidas de la Secretaría de Ambiente de la Nación. Ambos indicadores son comparables con el SIDSA.

En resumen, se analizaron y evaluaron para todo el sistema 43 indicadores de interrelación, de los cuales 33 pertenecen a la dimensión ambiental. De ese total, 9 fueron seleccionados como imprescindibles, 9 son propuestos para ser desarrollados en una segunda o tercera etapa de incorporación al sistema y 15 no fueron incluidos en el SIEDLS-TDF. De los 9 seleccionados en primera instancia 7 pertenecían al SIDSA y 2 presentan características locales.

\section{CONCLUSIONES}

En el presente artículo nos propusimos seleccionar indicadores capaces de medir el subsistema ambiental y su relación con las restantes dimensiones, la social, la económica y la institucional para un sistema de información estadística que permita la planificación, monitoreo y medición del desarrollo local sostenible en la Provincia de Tierra del Fuego.

Dicho objetivo fue alcanzado obteniendo una selección de 16 indicadores que dan cuenta de la dimensión ambiental, de los cuales 7 son específicos del subsistema ambiental y 9 de las interrelaciones de este subsistema con los restantes. En este sentido el modelo conceptual propuesto por la CEPAL denominado Evaluación de la Sostenibilidad de América Latina y el Caribe (ESALC) y su correspondiente marco ordenador de forma sistemémica, presentan la flexibilidad necesaria para interpretar las características locales.

Es así como podemos confirmar que se responden los interrogantes presentados al inicio. Las metodologías utilizadas permitieron realizar un acabado conocimiento de la dinámica local y la disponibilidad de información estadística. Si bien hemos detectado la necesidad de 
procesamiento de gran parte de la información (Hermida, 2015, 2017), el modelo demostró adaptarse a la dinámica ambiental de la provincia y a la disponibilidad de información.

En síntesis, consideramos que la propuesta contribuye al monitoreo del desarrollo local sostenible, y en especial de la dinámica ambiental presentada en este trabajo, de la provincia de Tierra del Fuego.

\section{REFERENCIAS BIBLIOGRÁFICAS}

AROCENA, F. (2009). El desarrollo sustentable: ¿oxímoron o solución?. Trabajo presentado en Congress of the Latin American Studies Association, Rio de Janeiro, Brasil, del 11 al 14 de Junio de 2009.

AGUADO, I; BARRUTIA, J; y ECHEBARRIA, C (2008). Métricas para el desarrollo sostenible. Trabajo presentado en XI Jornadas de Economía Crítica, Eco-Cri, 27, 28 y 29 de marzo, Bilbao.

BUCKLEY, W. (1982). La sociología y la teoría moderna de los sistemas, Buenos Aires, Amorrortu Editores.

CARPINETTI, N.E., (2003). Perfil sociodemográfico de los migrantes a Tierra del Fuego en el marco regresivo de la situación económica provincial. Tesis de Maestría, Universidad Nacional de Luján. https://doi.org/10.17227/0123487043folios165.179

CAVUOTO, N. L. (2009). Herramientas para planificar el desarrollo: un Sistema de Información Territorial con enfoque de cadena de valor. Revista Territorios, 20-21, 175- 205. Recuperado de http://www.redalyc.org/articulo.oa?id=35714248009.

CEA D' ANCONA, M. A. (1996) Metodología Cuantitativa: Estrategias y Técnicas de Investigación Social. Ed. Síntesis. Madrid.

CONSEJO NACIONAL DE COORDINACIÓN DE POLÍTICAS SOCIALES (CNCPS) (2016a) Proceso de adaptación nacional, Unidad de Coordinación Técnica, Buenos Aires, Recuperado el 21 de octubre de 2016 de http://www.odsargentina.gob.ar/ public/documentos/seccion_publicaciones/ods/proceso_de_adaptacion_nacional.pdf consultado. https://doi.org/10.19137/pys-2018-250201

CONSEJO NACIONAL DE COORDINACIÓN DE POLÍTICAS SOCIALES (CNCPS) (2016b) Guía para el proceso de adaptación de los ODS en el gobierno provincial, Unidad de Coordinación Técnica, Buenos Aires, Recuperado 21 de octubre de 2016 en http://www.odsargentina.gob.ar/public/documentos/seccion_publicaciones/ods/guia_p ara_el_proceso_de_adaptacion_provincial.pdf. https://doi.org/10.2307/j.ctvdmwxbw.4

COOK, T.D. y REICHARDT, Ch. T. (1986) Capítulo 1, Hacia una superación del enfrentamiento entre los métodos cualitativos y los cuantitativos. Métodos cualitativos y cuantitativos en la investigación evaluativa. Ed. Morata. Madrid. https://doi.org/10.18381/eq.v3i2.2594

DE IMAZ, J. (1972) Los hombres del confín del mundo. Buenos Aires. EUDEBA.

GALLOPIN, G. (2003) Sostenibilidad y desarrollo sostenible: un enfoque sistémico, Santiago de Chile, CEPAL.

GALlOPÍN, G. (2006) Los Indicadores de Desarrollo Sostenible: Aspectos Conceptuales y Metodológicos. Trabajo presentado en el Seminario de Expertos sobre Indicadores de Sostenibilidad en la Formulación y Seguimiento de Políticas. Chile. https://doi.org/10.5209/rev_mare.2011.n11.38070

GLASER, G. y STRAUSS, A. (1967) El muestreo teórico (versión traducida). The discovery of grounded theory. Strategies for qualitative research. Cuadernos de Metodología de 
la Investigación en Ciencias Sociales, Cátedra Errandonea, Facultad de Ciencias Sociales, UBA. https://doi.org/10.2307/j.ctv7fmfjk.11

GOÑI, R, GOIN F. (2006) Marco Conceptual para la Definición del Desarrollo Sustentable. Salud Colectiva, 2, 191-198, Recuperado de http://www.unla.edu.ar/ saludcolectiva/revista05/7.Ricardo\%20Goni.pdf. https://doi.org/10.18294/sc.2006.65

GÓMEZ, A.; MASSÉ, G. y OLMOS, F. (2012) Sistemas nacionales de indicadores de 'desarrollo sostenible' (SNIDS) comparados en países seleccionados de América Latina, en 2010. Trabajo presentado en el V Congreso de la Asociación Latinoamericana de Población, Montevideo, Uruguay, del 23 al 26 de octubre de 2012. Recuperado. de http://www.alapop.org/Congreso2012/DOCSFINAIS_PDF/ ALAP_2012_FINAL600.pdf. https://doi.org/10.1787/888932532468

HERMIDA, M. (2009) Tratamiento estadístico de los registros administrativos. Trabajo presentado en el XXVII Congreso de la Asociación Latinoamericana de Sociología, Universidad de Buenos Aires. Recuperado de http://www.aacademica.com/000062/1156.pdf. https://doi.org/10.15517/psm.v13i1.19290

HERMIDA, M. (2012). Los sistemas de información local. Trabajo presentado en el X Congreso Latinoamericano de Sociedades de Estadística, Ciudad de Córdoba. Recuperado de http://conferencias.unc.edu.ar/index.php/xclatse/clatse2012/ paper/view/267/74 consultado el 13 de agosto de 2013. https://doi.org/10.1076/epri.10.10.12.6813

HERMIDA, M. (2015) Representaciones de actores estatales acerca del desarrollo en Tierra del Fuego. Revista Tensões Mundiais / World Tensions. 11(20), 163-184. Recuperado de http://www.tensoesmundiais.net/index.php/tm/article/view/334/448

HERMIDA, M. (2017). Los indicadores de la dimensión social del desarrollo sostenible, el caso de Tierra del Fuego. Revista Latinoamericana De Metodología De Las Ciencias Sociales, 7 (2), e029. Recuperado de https://doi.org/10.24215/18537863e029

HERMIDA, M. (2016) Hacia un sistema de información estadística para el monitoreo del desarrollo local sostenible en la Provincia de Tierra del Fuego, Argentina, Tesis de Maestría en Generación y Análisis de Información Estadística (MGAIE), UNTREF, Buenos Aires. https://doi.org/10.25145/j.pasos.2017.15.060

HERMIDA, M.; MALIZIA, M. y VAN AERT, P. (2013) Migración en Tierra del Fuego (o la historia de una ida y una vuelta). Sociedad Fueguina, 1 (2) Recuperado de http://200.61.137.30/pagina_2012/wp-content/uploads/2013/08/SociedadFueguina_ Nro24.pdf . https://doi.org/10.18411/d-2016-154

HERMIDA, M.; MALIZIA, M. y VAN AERT, P. (2016). Migración e identidad: El caso de Tierra del Fuego. Revista Identidades 6 (10), 34-52. Recuperado de https://iidentidadess.files.wordpress.com/2015/07/03-identidades-10-6-2016-hermidamalizia-vanaert.pdf ISSN 2250-5369.

HERMIDA, M., (2014) Los indicadores sociales desde la perspectiva del desarrollo local sostenible en Tierra del Fuego. Trabajo presentado en VIII Jornadas de Sociología de la UNLP, Ensenada, 3, 4 y 5 de diciembre de 2014, Departamento de Sociología de la Facultad de Humanidades y Ciencias de la Educación (UNLP), La Plata. Recuperado de http://jornadassociologia.fahce.unlp.edu.ar/viii-jornadas-2014/PONmesa19 Hermida.pdf/view?searchterm=None. https://doi.org/10.19137/qs.v7i0.686

HERMIDA, M., MALIZIA, M., MARTINEZ CUGAT, J.A., y OYARZO, L., (2014) Historia, procesos económicos y conformación institucional del Estado y las organizaciones del sistema productivo de Tierra del Fuego. Trabajo presentado en VI Jornadas de Historia de la Patagonia, del 12 al 14 de noviembre de 2014, Facultad de Ciencias de la Educación, Universidad Nacional del Comahue, Cipolletti, Río Negro. https://doi.org/10.21840/siic/151343 
HERNÁNDEZ SAMPIERI, R. , FERNÁNDEZ, C. Y BAPTISTA, P. (2010) Metodología de la Investigación. Ed.MacGraw-Hill. México.

HOPWOOD, B. MELLOR, M. y O'BRIEN, G. (2005) Sustainable Development: Mapping Different Approache. Sustainable Development, 13, 38-52 Recuperado de www.interscience.wiley.com. https://doi.org/10.1002/sd.244

LAZARSFELD, P. (1973). "De los conceptos a los índices empíricos". En Raymond Boudon y P Lazarsfeld, Metodología de las ciencias sociales, Vol I, Conceptos e Indices, Barcelona, Laia. https://doi.org/10.7203/dces.26.1929

LIVRAGHI, E. (2011) Los ovejeros del fin del mundo y su relación con la tecnología, Tesis para optar al grado de Magíster en Estudios Sociales Agrarios. Facultad Latinoamericana de Ciencias Sociales (FLACSO) Sede Argentina. https://doi.org/10.14482/eidos.26.8744

LUIZ., M.T. y SCHILLAT, M., (1997). La Frontera Austral, Tierra del Fuego, 1520-1920. Cadiz, Universidad de Cadiz.

MADOERY, O (2016) Los Desarrollos Latinoamericanos y sus Controversias. Colección Territorios, Ushuaia, Ediciones UNTDF

MANTÉ, M. Y HERMIDA, M. (2016) ODS: La salud pública en la agenda del desarrollo sostenible. Revista de los Colegios de Médicos Veterinarios de la Patagonia 31 (31), Diciembre de 2016, Vet Comunicaciones, Santa Fé. https://doi.org/10.17103/reei.31.25

MARTÍNEZ, A. y PÉREZ, V. (2014). Habitar nuestro suelo: Una aproximación a la realidad habitacional de Tierra del Fuego. Sociedad Fueguina, 2 (3). Recuperado de http://200.61.137.30/pagina_2012/wp-content/uploads/2013/08/SociedadFueguina _Nro3.pdf . https://doi.org/10.18411/d-2016-154

MAYNTZ, R. (1985): Algunas premisas metodológicas. Introducción a los métodos de la sociología empírica. Madrid. Alianza Editorial.

MASTROSCELLO, M. (2007) La economía del Fin del Mundo, Configuración, evolución y perspectivas económicas de Tierra del Fuego. Ushuaia. Editorial cuatro vientos.

ORGANIZACIÓN DE LAS NACIONES UNIDAS (ONU) (1987). Nuestro futuro común. Informe de la Comisión Mundial sobre el Medio Ambiente y el Desarrollo. Recuperado el 15 de agosto de 2013 de http://www.un.org /es/comun/docs/?symbol=A/42/427. https://doi.org/10.2307/j.ctv75d9g9.19

ORGANIZACIÓN DE LAS NACIONES UNIDAS (ONU) (2015) Transformar nuestro mundo: la Agenda 2030 para el Desarrollo Sostenible, Resolución de la Asamblea General de las Naciones Unidas, 18 de Septiembre de 2015. Recuperado el 23 de octubre de 2016 de http://www.un.org/ga/search/view_doc.asp?symbol=A/ 70/L.1\&Lang=S. https://doi.org/10.18356/adb98973-es

PIOVANI, J. (2008) Producción y reproducción de sentidos en torno a lo cualitativo y lo cuantitativo en la sociología. COHEN, N. Y J. PIOVANI (comp), La metodología de la investigación en debate, La Plata: EUDEBA y EDULP. https://doi.org/10.4995/aniav.2015.1217

QUETGLAS, F. (2008) Qué es el desarrollo local: territorio, política y economía. Buenos Aires, Capital Intelectual.

QUIROGA MARTÍNEZ, R. (2009) Guía metodológica para desarrollar indicadores ambientales y de desarrollo sostenible en países de América Latina y el Caribe, CEPAL, Santiago de Chile. Recuperado de http://archivo.cepal.org/pdfs/2009/ S0900307.pdf consultado el 14 de mayo de 2015. https://doi.org/10.4067/s025071612006000200002

REBORATTI, C. (2000) Ambiente y Sociedad. Conceptos y relaciones. Buenos Aires: Editorial Planeta. 
RITZER, G (2001) La teoría sociológica moderna - Teoría de sistemas, Madrid: McGrawHill.

ROMANO, S. (2015) Tensiones en la cadena de valor foresto- industrial. El caso de Tierra del Fuego. Elementos de política pública. Tesis de Maestría en Economía y Desarrollo industrial con mención en la PyME, Universidad Nacional de General Sarmiento y Universidad Nacional de Mar del Plata. https://doi.org/10.19137/qs.v13i0.6

SECRETARÍA DE AMBIENTE Y DESARROLLO SUSTENTABLE DE LA NACIÓN (SAyDS) (Ed.). (2005). Sistema de Indicadores de Desarrollo Sostenible. Argentina. Buenos Aires, Ministerio de Salud y Ambiente de la Nación, SAyDS.

SECRETARÍA DE AMBIENTE Y DESARROLLO SUSTENTABLE DE LA NACIÓN (SAyDS) (Ed.). (2010). Sistema de Indicadores de Desarrollo Sostenible. Argentina. Buenos Aires, Jefatura de Gabinete de Ministros, SAyDS. https://doi.org/10.18271/ria.2017.277

SECRETARÍA DE AMBIENTE Y DESARROLLO SUSTENTABLE DE LA NACIÓN (SAyDS) (Ed.). (2015). Sistema de Indicadores de Desarrollo Sostenible. Argentina. Buenos Aires, Jefatura de Gabinete de Ministros, SAyDS. https://doi.org/10.18271/ria.2017.277

SOTELO, J, TOLÓN, A y LASTRA, X (2011) Indicadores por y para el desarrollo sostenible, un estudio de caso. Estudios Geográficos, 72 (271), 611-654. Recuperado de https://doi.org/10.3989/estgeogr.201124

SCHORR, M y PORCELLI, L (2013) Industria electrónica de consumo en Tierra del Fuego. Régimen promocional, perfil de especialización y alternativas de desarrollo sectorial en la posconvertibilidad. Documentos de investigación social, 26 (26), San Martín: IDAES-UNSAM.

SVAMPA, M. (2009) La disputa por el desarrollo: territorio, movimientos de carácter socioambiental y discursos dominantes. Recuperado de http://www.maristellasvampa.net/ archivos/ensayo43.pdf

UNFPA (2014) Guías para la recolección y análisis de datos sociodemográficos a utilizar en situaciones de crisis humanitarias en América Latina y el Caribe. Panamá: UNFPA. Recuperado de http://lac.unfpa.org/sites/lac.unfpa.org/files/pub-pdf/Guias\%20 UNFPA-Esp.\%20\%28standard\%29.pdf . https://doi.org/10.1787/9789264259027graph6-es

VALLES, M. (1997) Técnicas Cualitativas de Investigación Social. Ed. Síntesis. Madrid. 